\title{
The association between personality traits and placebo effects: A preregistered systematic review and meta-analysis
}

\author{
Heemin Kang', Miriam S. Miksche', and Dan-Mikael Ellingsen ${ }^{1,2}$
}

\begin{abstract}
Placebo effects are ubiquitous yet highly variable between individuals, and therefore strongly impact clinical trial outcomes. It is unclear whether dispositional psychological traits influence responsiveness to placebo. This preregistered meta-analysis and systematic review synthesized the literature investigating the association between personality traits and placebo effects. Based on 19 studies with $7 / 2$ participants, we performed formal meta-analyses for 10 different personality traits. We did not find evidence of associations between any of these traits and magnitude of placebo effects, which was supported by equivalence tests. Furthermore, we did not find evidence for moderating factors such as placebo manipulation type (Conditioning, non-conditioning) or condition (pain, non-pain). However, the current synthesis was not statistically powered for full inquiry into potential conditional or interactive associations between personality and situational variables. These findings challenge the notion that personality influences responsiveness to placebos and contradict its utility for identifying placebo "responders" and "non-responders".
\end{abstract}

\section{Keywords}

placebo effects, personality traits, systematic review, meta-analysis

\footnotetext{
' Department of Psychology, University of Oslo, Norway

${ }^{2}$ Department of Diagnostic Physics, Division of Radiology and Nuclear Medicine, Oslo University Hospital, Oslo, Norway Corresponding Authors:

Heemin Kang, Department of Psychology, University of Oslo, Forskningsveien 3A, 0373 Oslo, Norway, Email: heemk@student.sv.uio.no; Dan-Mikael Ellingsen, Department of Diagnostic Physics, Division of Radiology and Nuclear Medicine, Oslo University Hospital, N-0027 Oslo, Norway, Email: d.m.ellingsen@psychologi.uio.no.
} 


\section{Introduction}

The placebo effect - i.e. the therapeutic improvement following the administration of an inert treatment - is commonly used as a scientific model for investigating how expectations, cognition, and affect can influence sensory experiences and symptoms (Atlas, 2021). On the other hand, the large variability in individual placebo effects cause problems for clinical trials, which aim to assess the specific effects of drugs or interventions (Walach et al., 2005). The idea that individual responsiveness to placebo effects can be explained, to some extent, by stable psychological factors such as personality, has a long history (S. Fisher \& Fisher, 1963; Jellinek, 1946; Lasagna et al., 1954), and is widespread both in research and among clinical trialists today (Frisaldi et al., 2018; Pecina et al., 2013; Schedlowski et al., 2015; Vachon-Presseau et al., 2018; Weimer et al., 2015, p. 2). Personality traits can be defined as "consistent patterns of thoughts, feelings, and actions across developmental periods and contexts"(McCrae \& Costa, 2003), and are thought to play a key role in various clinical contexts, especially in psychiatry and clinical psychology. While placebo effects have been linked to a range of different personality traits (Darragh et al., 2014; Geers et al., 2010; Schweinhardt et al., 2009), some researchers have questioned the existence of a "placebo personality" and even the notion of individual consistency in placebo responsiveness (Buckalew et al., 1981; Kaptchuk et al., 2008; Shapiro et al., 1973, 1975). Despite a wealth of studies of different candidate traits associated with a "placebo personality" (Jakšić et al., 2013; Kern et al., 2020), there is currently no meta-analytic evidence for whether personality traits influence placebo effects.

In clinical trials, especially in the fields of pain, depression, and mood disorders, high placebo responses are often seen as essentially raising the bar for drug arms to "beat" the placebo response (Enck et al., 2013), contributing to many clinical trials failing to find significant effects. To address this issue, clinical trials have employed various methods to reduce, or control for, placebo response rate, e.g. trying to identify (and sometimes exclude (Bosman et al., 2021; Scott et al., 2021)) people who would respond favorably to placebos (Jellinek, 1946; Trivedi et al., 2018). Following the emergence of modern randomized controlled trials in the 1940s-50s, it was soon suggested that individuals may show a consistent tendency to respond ("placebo reactor") or not respond ("placebo non-reactor") positively to placebos (Beecher et al., 1953), and that this tendency may be explained by personality traits. An early influential study, using Rorschach interviews in patients receiving treatment for post-operative pain, found that consistent "placebo reactors" were more frequently "talkative, churchgoing, anxious, self-centered, interoceptive, and emotionally labile", compared to non-reactors (Lasagna et al., 1954). They speculated that such individuals may be "more dependent on outside stimulation than on their own mental processes" in order to relieve anxiety and tension, which in turn made them respond positively to placebo treatment. Subsequent studies reported that placebo reactors scored higher on "social acquiescence", or social desirability, which are related concepts for the tendency to conform to, or agree with, others' suggestions irrespective of the content (S. Fisher \& Fisher, 1963; McNair et al., 1979). Along similar lines, hypnotic suggestibility (Leigh et al., 2003) and agreeableness (Kelley et al., 2009) have more recently been linked to higher placebo responding. Building on these concepts, recent theoretical frameworks have proposed that "inward" and "outward" orientation may predispose individuals to respond to placebos depending on context (Darragh et al., 2015). Several additional modern hypotheses on the "placebo personality" have been pursued.

First, positive expectations of a beneficial therapeutic outcome is commonly considered a key contextual mechanism of placebo effects (Kirsch, 1985; Schwarz et al., 2016) . Correspondingly, dispositional optimism has been proposed to promote placebo effects by increasing the expectancy of a positive therapeutic outcome (Darragh et al., 2015; Geers et al., 2005, 2007, 2010; Kern et al., 2020; Scheier \& Carver, 1992). Conversely, more pessimistic people may react more saliently to information about adverse outcomes and side effects, which in turn may contribute to nocebo effects. Trait anxiety, which is sometimes negatively associated with optimism (Scheier et al., 1994), and related to negative expectancy bias (Cabeleira et al., 2014) has been suggested as a negative predictor of placebo responsiveness (Broelz et al., 2019; Horing et al., 2014; Morton et al., 2009; Pecina et al., 2013). Similarly, neuroticism (Pecina et 
al., 2013), pain catastrophizing(Sullivan et al., 2008), fear of pain (Corsi \& Colloca, 2017; Lyby et al., 2010) have been linked to placebo effects as a negative predictor.

Second, in line with previous findings suggesting that placebo improvement is underpinned by brain circuitry supporting reward and valuation mechanisms (Ashar et al., 2017; De la Fuente-Fernández et al., 2001; Ellingsen et al., 2013; Fields, 2004; Lidstone et al., 2005; Mayberg et al., 2002; Oken et al., 2008; Petrovic et al., 2002; Scott et al., 2007, 2008), another central hypothesis is that traits related to behavioral activation and reward responsiveness may be a positive predictor of placebo responsivity (De Pascalis \& Scacchia, 2019; Schweinhardt et al., 2009). Conversely, behavioral inhibition has been linked to anxiety (Carver \& White, 1994), and thus may be negatively associated with placebo improvement (Broelz et al., 2019).

Finally, since placebo-related improvement is influenced by the social context, such as qualities of a patient-clinician interaction (Ellingsen et al., 2020; Kelley et al., 2009) or by observing what happens to others who receive the same treatment (Colloca \& Benedetti, 2009; Schenk \& Colloca, 2020), traits related to dispositional empathy have been hypothesized to promote placebo effects(Davis, 1983). A general hypothesis is that an individual who scores high on empathy, and thus better internalizes others' experience, may be more likely to form a positive expectation after observing other participants' symptom improvement (Colloca \& Benedetti, 2009; Hunter et al., 2014; Valentini et al., 2014).

Although the role of personality in placebo effects has been subject to extensive research, no studies have yet systematically investigated the evidence for such associations using metaanalysis. We therefore aimed to systematically review and meta-analytically assess the associations between personality traits and placebo effects across different conditions. For each identified personality trait, we synthesized correlation coefficients between individual trait scores and magnitude of placebo effect. Next, we tested if factors such as condition (pain, nonpain), placebo manipulation type (conditioning, non-conditioning), and placebo administration method (drug, non-drug) could explain heterogeneity between studies. Finally, we investigated the degree to which the results were influenced by outliers, publication year, study quality, or the inclusion of unpublished studies.

\section{Results}

\section{Study selection and identified studies}

We performed a systematic database search and identified 2,211 records in total (see Methods for full details). After removing duplicates and non-primary studies (e.g., re-analysis of existing data, conference abstracts, books, and protocols for pilot studies), 1226 reports were sought for retrieval of full text. 13 records were additionally identified via citation searching and suggestions from study authors. 1114 reports were retrieved and assessed for eligibility, and a total of 30 experimental studies with 294 effect measures were identified for this review. These studies included a total of 1310 participants (mean \pm SD age: $35.41 \pm 24.52$ ). An overview of the study selection process is presented in Figure 1.

A total of 24 studies assessed pain outcomes induced by pressure (Ellingsen et al., 2020; Whalley et al., 2008), heat stimulation (Corsi \& Colloca, 2017; Eippert et al., 2009; Ellingsen et al., 2014; Geisler et al., 2020; Huber et al., 2013; Kessner et al., 2014; Meyer et al., 2015; Ruscheweyh et al., 2014; Schweinhardt et al., 2009; Stein et al., 2012; Weimer et al., 2019), electric stimulation (Colloca et al., 2010; Colloca \& Benedetti, 2009; Hunter et al., 2014; Meyer et al., 2019; Rosen et al., 2017; Tang et al., 2019), laser (Valentini et al., 2014), saline injection (Lund et al., 2015; Pecina et al., 2013), and cold stimulation (De Pascalis \& Scacchia, 2017, 2019). Seven studies used non-pain outcomes, including tactile perception induced by electric stimulation (Colloca et al., 2010), brush touch (Ellingsen et al., 2014; Ellingsen et al., 2013), warm touch (Ellingsen et al., 2013), stress (Darragh et al., 2014), experience of extraordinary events (Maij \& van Elk, 2018), exercise performance (Saunders et al., 2019), and disgust (Zorjan et al., 2019). Expectations of positive therapeutic effects were induced by verbal suggestion (Colloca \& Benedetti, 2009; Darragh et al., 2014; De Pascalis \& Scacchia, 2017, 2019; Eippert et al., 2009; Ellingsen et al., 2014; Ellingsen et al., 2013; Hunter et al., 2014; Lund et al., 2015; Meyer et al., 2015, 2019; Pecina et al., 2013; Rosen et al., 2017; Ruscheweyh et al., 2014; Saunders et al., 2019; Stein et al., 2012; Whalley et al., 2008; Zorjan et al., 2019), social observation (Colloca \& Benedetti, 2009; Ellingsen et al., 2020; Hunter et al., 2014; Maij \& van 
Elk, 2018), and conditioning (Colloca et al., 2010; Colloca \& Benedetti, 2009; Corsi \& Colloca, 2017; Geisler et al., 2020; Huber et al., 2013; Hunter et al., 2014; Kessner et al., 2014; Schweinhardt et al., 2009; Tang et al., 2019; Valentini et al., 2014; Weimer et al., 2019). Eighteen studies used a medicine/drug-based placebo, including topical cream (De Pascalis \& Scacchia, 2017, 2019; Eippert et al., 2009; Geisler et al., 2020; Ruscheweyh et al., 2014; Schweinhardt et al., 2009; Stein et al., 2012; Weimer et al., 2019; Whalley et al., 2008), pill or capsule (Saunders et al., 2019; Zorjan et al., 2019), inhalation of gas (Meyer et al., 2019), nasal spray (Darragh et al., 2014; Ellingsen et al., 2014; Ellingsen et al., 2013; Meyer et al., 2015), injection (Lund et al., 2015; Pecina et al., 2013). Nine studies used a non-drug approach, including placebo devices such as sham analgesic stimulation (Ellingsen et al., 2020; Rosen et al., 2017; Tang et al., 2019) and helmet (Maij \& van Elk, 2018), and visual cues that were conditioned with sham analgesic stimulation (Colloca \& Benedetti, 2009; Corsi \& Colloca, 2017; Huber et al., 2013; Hunter et al., 2014; Valentini et al., 2014). Characteristics of identified studies are summarized in Table S3.

\section{Included studies}

A total of 19 studies with 171 effect sizes were included in the final synthesis. Characteristics of included studies are summarized in Table 1. Since some studies reported multiple effect sizes, we used Robust Variance Estimation (RVE) to control for shared variance between such effect sizes. In order to meet the statistical assumptions for RVE, we applied an a priori decision rule for inclusion in data synthesis for each identified personality trait. Specifically, we performed formal meta-analysis for traits in which 1) there were five or more independent observations and 2) degrees of freedom exceeded the cutoff number of effect estimates, $d f s>4$, adjusted for small sample. Consequently, association between placebo effects and the following traits were not included in the final meta-analyses: absorption (Darragh et al., 2014; Lund et al., 2015; Maij \& van Elk, 2018; Whalley et al., 2008); pain catastrophizing (Corsi \& Colloca, 2017; Ellingsen et al., 2020; Geisler et al., 2020; Ruscheweyh et al., 2014; Weimer et al., 2019); anhedonia, tactile communication (Ellingsen et al., 2014; Ellingsen et al., 2013); social desirability (Eippert et al., 2009; Ellingsen et al., 2020; Geisler et al., 2020); fear of pain (Corsi \& Colloca, 2017; Huber et al., 2013); agreeableness (Corsi \& Colloca, 2017; Geisler et al., 2020; Pecina et al., 2013); openness (Corsi \& Colloca, 2017; Geisler et al., 2020); extraversion (Corsi \& Colloca, 2017; Darragh et al., 2014; Geisler et al., 2020); neuroticism (Corsi \& Colloca, 2017; Darragh et al., 2014; Geisler et al., 2020; Pecina, Love, et al., 2013; Rosen et al., 2017); conscientiousness (Corsi \& Colloca, 2017; Geisler et al., 2020); disgust proneness/sensitivity (Zorjan et al., 2019); interoceptive awareness (Geisler et al., 2020); suggestibility (Corsi \& Colloca, 2017; De Pascalis \& Scacchia, 2019; Huber et al., 2013; Lund et al., 2015); spirituality/religiosity/paranormal belief (Maij \& van Elk, 2018). 
Identification of studies via databases and registers

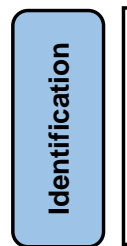

Records identified from:
- Web of Science $(n=319)$

- Embase $(n=744)$

- PubMed $(n=666)$

- JIPS database $(n=282)$

- Google Scholar $(n=200)$
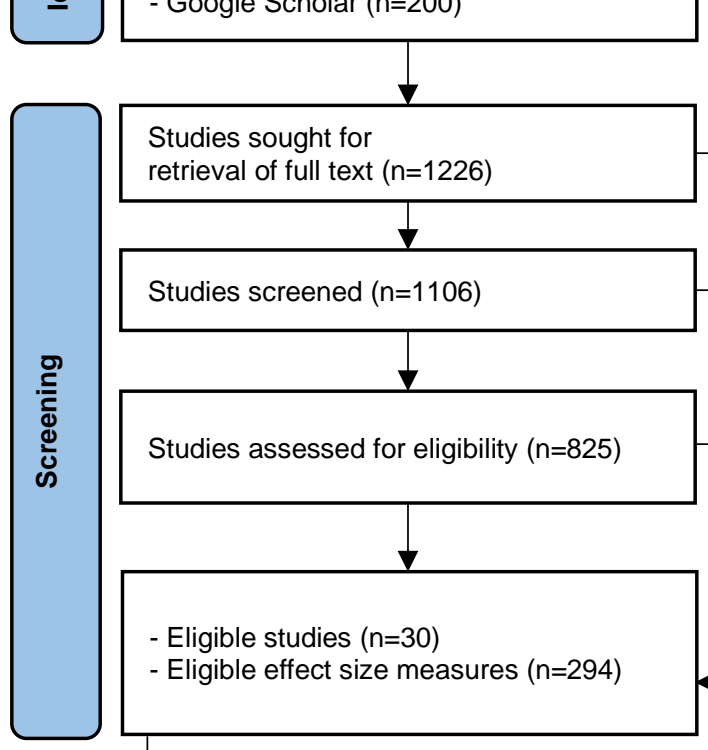

Studies sought for

retrieval of full text $(n=1226)$
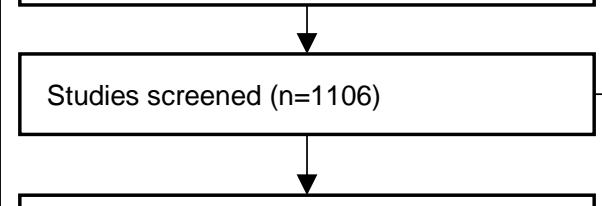

\section{Studies assessed for eligibility $(n=825)$}

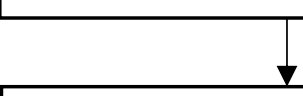

- Eligible studies ( $n=30)$

- Eligible effect size measures $(n=294)$
Studies removed before screening:

- Duplicate records removed $(n=699)$

- Records removed for other reasons $(n=286)$

Studies not retrieved $(n=120)$

Studies excluded $(n=281)$

\section{Studies excluded:}

- Lacking no-treatment control $(n=614)$

- Between-group comparison $(n=132)$

- Lacking personality data $(n=38)$

- Missing data $(n=12)$

- Duplicate $(\mathrm{n}=2)$
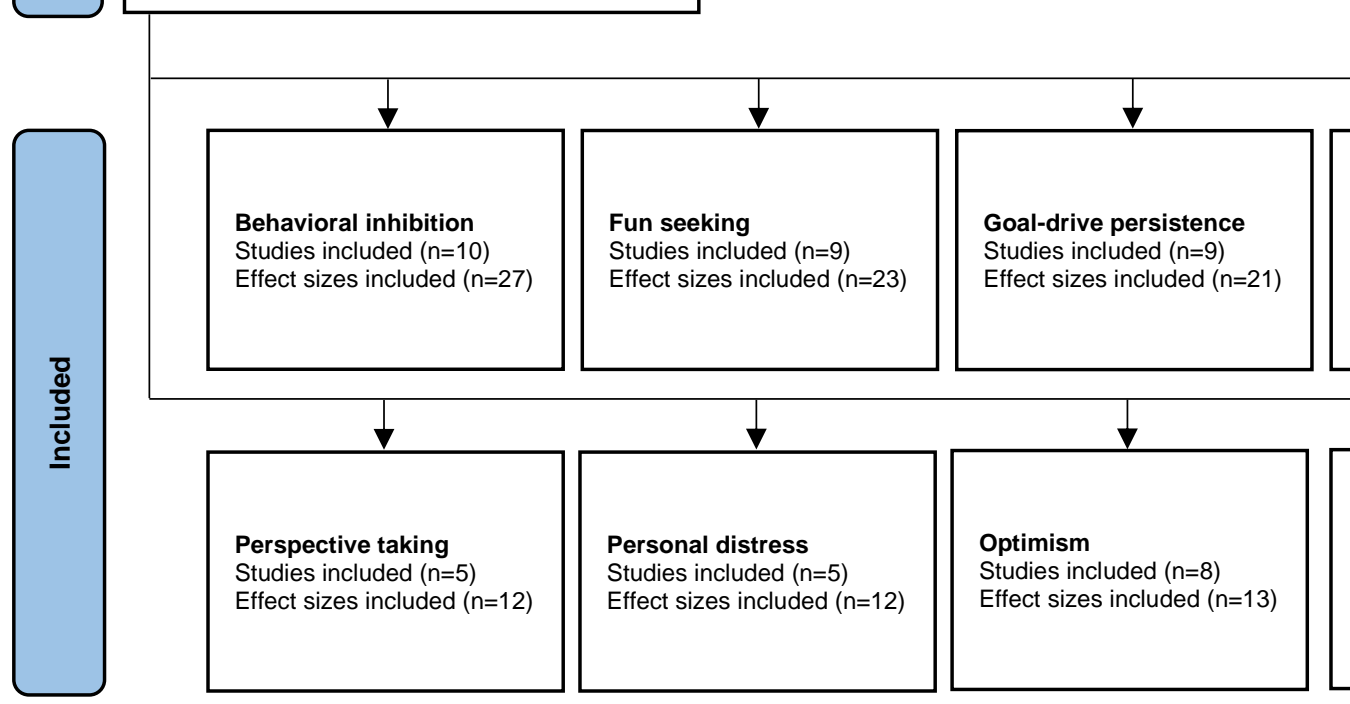

\section{Identification of studies via other methods}

Studies identified from:

- Citation searching $(n=10)$

- Suggested by authors $(n=3)$

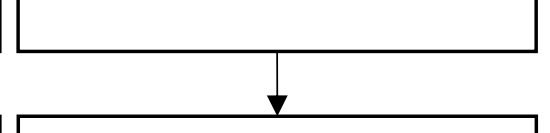

Studies sought for retrieval $(n=13)$

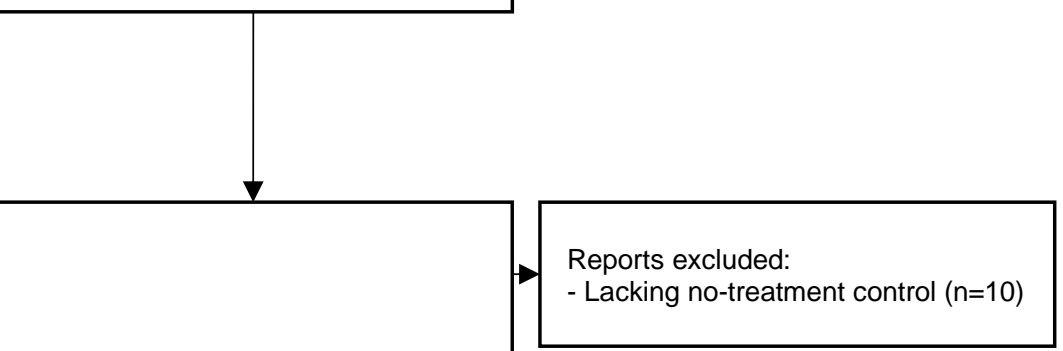

Studies assessed for eligibility $(n=13)$

Empathic Concern

Empathic Concern
Studies included $(n=6)$

Effect sizes included $(n=16)$

Effect sizes included $(n=27)$

(

Studies included $(n=5)$

Effect sizes included $(n=12)$

Figure I. Prisma 2020 flow diagram

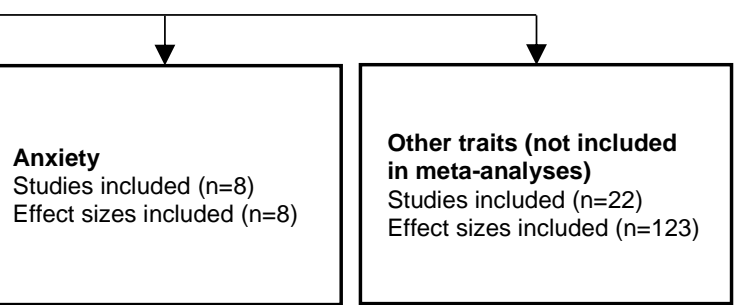


Table I. Characteristics of studies included in meta-analyses

\begin{tabular}{|c|c|c|c|c|c|c|c|c|c|c|}
\hline Author & Status & $\mathbf{N}$ & $\begin{array}{l}\text { Mean } \\
\text { age }\end{array}$ & $\begin{array}{l}\text { Sex } \\
(\% \mathbf{F})\end{array}$ & Condition & $\begin{array}{c}\text { Placebo ma- } \\
\text { nipulation }\end{array}$ & $\begin{array}{l}\text { Type of pla- } \\
\text { cebo }\end{array}$ & Blinding & $\begin{array}{l}\text { Outcome meas- } \\
\text { ure }\end{array}$ & Personality trait(s) ${ }^{a}$ \\
\hline \multirow{3}{*}{$\begin{array}{l}\text { Colloca \& } \\
\text { Benedetti } \\
(2009)\end{array}$} & $\begin{array}{l}\text { Non-clin- } \\
\text { ical }\end{array}$ & 16 & 21.7 & 100 & Pain - electrode & $\begin{array}{l}\text { Social observa- } \\
\text { tion }\end{array}$ & Visual cue & Single & Pain intensity & $\begin{array}{l}\text { Empathic concern } n^{\mathrm{b}} \text {, fantasy } \mathrm{b}^{\mathrm{b}} \text {, per- } \\
\text { spective-taking } \\
\text { tress } \text { persal dis- }^{\mathrm{b}} \text {, }\end{array}$ \\
\hline & $\begin{array}{l}\text { Non-clin- } \\
\text { ical }\end{array}$ & 16 & 22.8 & 100 & Pain - electrode & Conditioning & Visual cue & Single & Pain intensity & $\begin{array}{l}\text { Empathic concern } \text {, fantasy }^{\mathrm{b}} \text {, per- } \\
\text { spective-taking }{ }^{\mathrm{b}} \text {, personal dis- } \\
\text { tress }^{\mathrm{b}}\end{array}$ \\
\hline & $\begin{array}{l}\text { Non-clin- } \\
\text { ical }\end{array}$ & 16 & 23.5 & 100 & Pain - electrode & Verbal suggestion & Visual cue & Single & Pain intensity & $\begin{array}{l}\text { Empathic concern }{ }^{\mathrm{b}} \text {, fantasy }{ }^{\mathrm{b}} \text {, per- } \\
\text { spective-taking }{ }^{\mathrm{b}} \text {, personal dis- } \\
\text { tress }^{\mathrm{b}}\end{array}$ \\
\hline $\begin{array}{l}\text { Eippert et al. } \\
\text { (2009) }\end{array}$ & $\begin{array}{l}\text { Non-clin- } \\
\text { ical }\end{array}$ & 40 & 26.1 & 0 & Pain - heat & Verbal suggestion & Topical cream & Double & Pain intensity & Anxiety $^{c}$ \\
\hline $\begin{array}{l}\text { Schweinhardt } \\
\text { et al. } \\
(2009)\end{array}$ & $\begin{array}{l}\text { Non-clin- } \\
\text { ical }\end{array}$ & 22 & 27.4 & 79.5 & Pain - heat & Conditioning & Topical cream & Single & Pain intensity & $\begin{array}{l}\text { Behavioral inhibition d, goal-drive } \\
\text { persistence, fun seekingd,e, re- } \\
\text { ward responsiveness }\end{array}$ \\
\hline $\begin{array}{l}\text { Stein et al. } \\
(2012)\end{array}$ & $\begin{array}{l}\text { Non-clin- } \\
\text { ical }\end{array}$ & 24 & 26.1 & 0 & Pain - heat & Non-conditioning & Drug & Single & Pain intensity & Anxietyc $^{c}$ \\
\hline $\begin{array}{l}\text { Ellingsen et al. } \\
\text { (2013) }\end{array}$ & $\begin{array}{l}\text { Non-clin- } \\
\text { ical }\end{array}$ & 28 & 25.5 & 33.3 & $\begin{array}{l}\text { Pain - heat, } \\
\text { Soft touch, } \\
\text { Warm touch }\end{array}$ & Verbal suggestion & Nasal spray & Double & $\begin{array}{l}\text { Pain unpleasant- } \\
\text { ness, } \\
\text { Touch pleasantness, } \\
\text { Warmth pleasant- } \\
\text { ness }\end{array}$ & $\begin{array}{l}\text { Behavioral inhibitione, fun seek- } \\
\text { inge, goal-drive persistencee, re- } \\
\text { ward responsiveness }^{\mathrm{e}} \text {, optimism }\end{array}$ \\
\hline $\begin{array}{l}\text { Darragh et al. } \\
(2014)\end{array}$ & $\begin{array}{l}\text { Non-clin- } \\
\text { ical }\end{array}$ & 29 & 20.5 & 69 & Stress & Verbal suggestion & Nasal spray & Single & Self-reported stress & $\begin{array}{l}\text { Empathic concern }{ }^{\mathrm{b}} \text {, fantasy }{ }^{\mathrm{b}} \text {, per- } \\
\text { spective-taking }^{\mathrm{b}} \text {, personal dis- } \\
\text { tress }^{\mathrm{b}} \text {, behavioral inhibitione, fun } \\
\text { seekinge, goal-drive persistencee, }^{\mathrm{e}} \\
\text { reward responsiveness }^{\mathrm{e}} \text {, opti- } \\
\text { mism }^{\mathrm{f}}\end{array}$ \\
\hline $\begin{array}{l}\text { Ellingsen et al. } \\
\text { (2014) }\end{array}$ & $\begin{array}{l}\text { Non-clin- } \\
\text { ical }\end{array}$ & 42 & 25.4 & 66.7 & $\begin{array}{l}\text { Pain - heat, soft } \\
\text { touch }\end{array}$ & Verbal suggestion & Nasal spray & Double & $\begin{array}{l}\text { Pain unpleasant- } \\
\text { ness, } \\
\text { Pain intensity, } \\
\text { Touch pleasantness, } \\
\text { Touch intensity }\end{array}$ & $\begin{array}{l}\text { Behavioral inhibitione, fun seek- } \\
\text { inge, goal-drive persistence', re- } \\
\text { ward responsivenesse }^{\mathrm{e}} \text {, optimism }\end{array}$ \\
\hline \multirow{4}{*}{$\begin{array}{l}\text { Hunter et al. } \\
(2014)\end{array}$} & \multirow{4}{*}{$\begin{array}{l}\text { Non-clin- } \\
\text { ical } \\
\text { Non-clin- } \\
\text { ical } \\
\text { Non-clin- } \\
\text { ical } \\
\text { Non-clin- } \\
\text { ical }\end{array}$} & 15 & 25.2 & 100 & Pain - electrode & $\begin{array}{l}\text { Social observa- } \\
\text { tion via video }\end{array}$ & Visual cue & Single & Pain intensity & Empathic concern ${ }^{b}$ \\
\hline & & 15 & 29.0 & 100 & Pain - electrode & $\begin{array}{l}\text { Social observa- } \\
\text { tion in person }\end{array}$ & Visual cue & Single & Pain intensity & Empathic concern ${ }^{\mathrm{b}}$ \\
\hline & & 15 & 23.3 & 100 & Pain - electrode & Verbal suggestion & Visual cue & Single & Pain intensity & Empathic concern ${ }^{\mathrm{b}}$ \\
\hline & & 15 & 30.9 & 100 & Pain - electrode & Conditioning & Visual cue & Single & Pain intensity & Empathic concern ${ }^{\mathrm{b}}$ \\
\hline $\begin{array}{l}\text { Valentini et al. } \\
(2014)\end{array}$ & $\begin{array}{l}\text { Non-clin- } \\
\text { ical }\end{array}$ & 27 & 22.8 & 44.4 & Pain - laser & Conditioning & Visual cue & Single & $\begin{array}{l}\text { Pain intensity, Pain } \\
\text { unpleasantness }\end{array}$ & $\begin{array}{l}\text { Empathic concern }{ }^{\mathrm{b}} \text {, fantasy }{ }^{\mathrm{b}} \text {, per- } \\
\text { spective-taking }{ }^{\mathrm{b}} \text {, personal dis- } \\
\text { tress }^{\mathrm{b}} \text {, behavioral inhibitione, fun } \\
\text { seekinge, goal-drive persistence }^{\mathrm{e}}, \\
\text { reward responsiveness }^{\mathrm{e}}\end{array}$ \\
\hline $\begin{array}{l}\text { Meyer et al. } \\
\text { (2015) } \\
\text {-Study } 1 \\
\end{array}$ & $\begin{array}{l}\text { Non-clin- } \\
\text { ical }\end{array}$ & 26 & 25.7 & 46.7 & Pain - heat & Verbal suggestion & Nasal spray & Single & Fear rating & Anxiety ${ }^{c}$ \\
\hline
\end{tabular}




\begin{tabular}{|c|c|c|c|c|c|c|c|c|c|c|}
\hline $\begin{array}{l}\text { Meyer et al. } \\
(2015) \\
\text {-Study } 2\end{array}$ & $\begin{array}{l}\text { Non-clin- } \\
\text { ical }\end{array}$ & 26 & 26 & 48.3 & Pain - heat & Verbal suggestion & Nasal spray & Single & Fear rating & Anxiety $^{c}$ \\
\hline $\begin{array}{l}\text { Corsi \& Colloca } \\
(2017)\end{array}$ & $\begin{array}{l}\text { Non- } \\
\text { clinical }\end{array}$ & 46 & 27.4 & 52.2 & Pain - heat & Conditioning & Visual cue & Single & Pain intensity & $\begin{array}{l}\text { Anxietyc, behavioral inhibitione, g, } \\
\text { fun seekinge, g, goal-drive persis-' } \\
\text { tencee, reward responsiveness }\end{array}$ \\
\hline $\begin{array}{l}\text { De Pascalis \& } \\
\text { Scacchia } \\
\text { (2017) }\end{array}$ & $\begin{array}{l}\text { Non-clin- } \\
\text { ical }\end{array}$ & 52 & 23.4 & 100 & Pain - cold & Verbal suggestion & Topical cream & Single & $\begin{array}{l}\text { Pain intensity, } \\
\text { Pain distress }\end{array}$ & $\begin{array}{l}\text { Behavioral inhibition }{ }^{\mathrm{h}} \\
\text { fun seekingh, goal-drive persis- } \\
\text { tence }^{\mathrm{h}} \text {, reward responsiveness }\end{array}$ \\
\hline $\begin{array}{l}\text { De Pascalis \& } \\
\text { Scacchia } \\
\text { (2019) }\end{array}$ & $\begin{array}{l}\text { Non-clin- } \\
\text { ical }\end{array}$ & 58 & 24.5 & 100 & Pain - cold & Verbal suggestion & Topical cream & Single & $\begin{array}{l}\text { Pain intensity, } \\
\text { Pain distress }\end{array}$ & $\begin{array}{l}\text { Behavioral inhibition } \\
\text { fun-seekingh, goal-drive persis- } \\
\text { tence }{ }^{\mathrm{h}} \text {, reward responsiveness }\end{array}$ \\
\hline $\begin{array}{l}\text { Meyer et al. } \\
(2019)\end{array}$ & $\begin{array}{l}\text { Non-clin- } \\
\text { ical }\end{array}$ & 23 & 24.6 & 72.2 & Pain - electrode & Verbal suggestion & Gas & Single & Fear rating & Anxietyc \\
\hline $\begin{array}{l}\text { Saunders et al. } \\
\text { (2019) }\end{array}$ & $\begin{array}{l}\text { Non-clin- } \\
\text { ical }\end{array}$ & 28 & 36 & 100 & $\begin{array}{l}\text { Exercise per- } \\
\text { formance }\end{array}$ & Verbal suggestion & Capsule & Open-label & Time-to-completion & Optimism $^{\mathrm{f}}$ \\
\hline $\begin{array}{l}\text { Weimer et al. } \\
(2019)\end{array}$ & $\begin{array}{l}\text { Non-clin- } \\
\text { ical }\end{array}$ & 78 & 27.4 & 79.5 & Pain - heat & Conditioning & Topical cream & Single & Pain intensity & $\begin{array}{l}\text { Sensitivity to punishmenti, sensi- } \\
\text { tivity to reward }\end{array}$ \\
\hline $\begin{array}{l}\text { Ellingsen et al. } \\
(2020)\end{array}$ & Clinical & 18 & 40.0 & 100 & Pain - pressure & $\begin{array}{l}\text { Social observa- } \\
\text { tion }\end{array}$ & $\begin{array}{l}\text { Electroacu- } \\
\text { puncture }\end{array}$ & Double & Pain intensity & 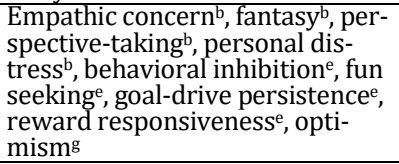 \\
\hline $\begin{array}{l}\text { Geisler et al. } \\
(2020)\end{array}$ & $\begin{array}{l}\text { Non-clin- } \\
\text { ical }\end{array}$ & 38 & 27.4 & 0 & Pain - heat & Conditioning & Topical cream & Single & Pain intensity & Anxietyc, optimism ${ }^{f}$ \\
\hline
\end{tabular}

a Only the traits included in meta-analyses are shown. For some studies, additional traits were collected (see Table S3 for more comprehensive details of each study); ${ }^{b}$ Interpersonal Reactivity Index; ${ }^{\mathrm{c}}$ State-Trait Anxiety Inventory; ${ }^{\mathrm{d}}$ Temperament Character Inventory; ${ }^{\mathrm{e}}$ Behavioral Inhibition/Activation System; ${ }^{\mathrm{f}}$ Revised Life Orientation Test; ${ }^{g}$ Tridimensional Personality Questionnaire; ${ }^{\text {h }}$ Reinforcement Sensitivity Theory Personality Questionnaire; ${ }^{\text {i }}$ Sensitivity to Punishment and Sensitivity to Reward Questionnaire 


\section{Associations between placebo effects and personality}

Summary effect sizes for placebo effect vs. trait score correlation coefficients were calculated for each personality trait using random-effects model with RVE incorporated in order to account for dependent outcomes. Meta-analysis was performed for correlation coefficients between placebo effect and each personality trait (i.e., Behavioral inhibition, Fun seeking, Goal-drive persistence, Reward responsiveness, Empathy - Perspective-taking, Fantasy, Personal distress, Empathic concern, Optimism, and Anxiety). In summary, we found no significant correlations between placebo effects and trait score for any of the personality traits $(r<0.14, \mathrm{P}>0.07)$ (Figure 2). Full details of the metaanalyses for each personality trait are provided in Figures S1-S10.

A non-significant result may reflect a true underlying null effect or the lack of statistical power to detect a true effect. To formally assess the evidence for the absence of a meaningful effect, we performed equivalence tests for each meta-analysis, using the two one-sided test (TOST) approach (Lakens, 2017). We compared equivalence bounds using $r= \pm 0.1, r= \pm 0.2$ and $r= \pm 0.3$ as the smallest effect sizes of interest, corresponding to conventional levels of small, medium and large effect sizes (Gignac \& Szodorai, 2016). Effect sizes (Pearson's $r$ coefficients) were converted to Cohen's $d$ prior to equivalence testing (TOSTER (Lakens, 2017)). Summary effect sizes for all traits were statistically equivalent to zero when using equivalence bounds of $r= \pm 0.3$, indicating evidence for an absence of any large effect (i.e. $r>0.3$ or $r<-0.3$ ) of personality on placebo effects. For equivalence bounds of $r= \pm 0.2$, associations between placebo responsiveness and Behavioral Inhibition, Fun seeking, Goaldrive persistence, and Optimism were statistically equivalent to zero. For small effects (equivalence bounds $r= \pm 0.1$ ), we did not find evidence for statistical equivalence. Thus, although there were no significant associations between placebo effects and any of the personality traits, we cannot rule out the possibility of a small effect $(r<0.2)$ that may be detected with increased statistical power.

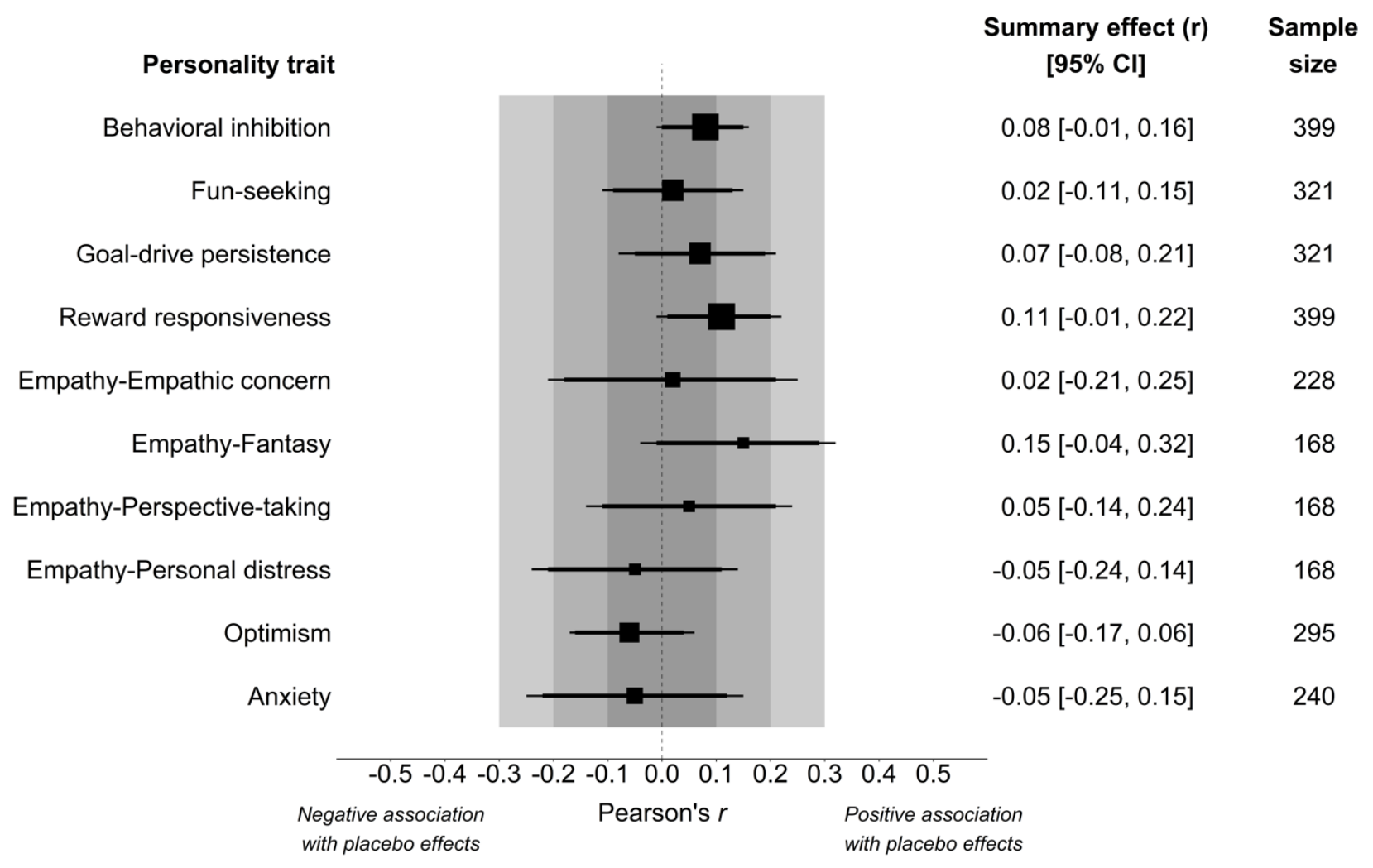

Figure 2. Summary of meta-analytic outcomes. The forest plot shows the summary effect of the placebo effect Vs. trait correlation for each personality trait. The size of each square (summary effect) corresponds to the total sample size, and the thin lines represent $95 \%$ confidence intervals $(\mathrm{Cl})$, relevant to the Robust Variance Estimation. A more positive summary effect reflects a positive association between a given personality trait and placebo effects - i.e. individuals with a high trait 
score would benefit more from placebo treatment - whereas a negative summary effect reflects a negative association between trait and placebo effect. The thick lines represent the $90 \% \mathrm{Cl}$, relevant to the two one-sided tests (TOST) for statistical equivalence. Specifically, a summary effect is equivalent to zero if the $90 \% \mathrm{Cl}$ does not extend past the upper or lower bounds (shaded in grey for bounds corresponding to $r= \pm 0.1, r= \pm 0.2$, and $r= \pm 0.3$ ).

\section{Influence of moderators}

Moderate or high heterogeneity across studies ( $\left.\mathrm{I}^{2}>25 \%\right)$ was observed for the traits Fun seeking $\left(I^{2}=27.70\right)$, Reward responsiveness $\left(I^{2}=29.73 \%\right)$, Empathy - Empathic Concern $\left(I^{2}=50.16 \%\right)$, and anxiety $\left(I^{2}=29.64 \%\right)$. We performed the following subgroup analyses to investigate potential sources of this heterogeneity, using a similar statistical approach as for the main meta-analyses $(\mathrm{k} \geq 5$ effect size estimates): placebo manipulation method (Conditioning, Non-conditioning) and condition studied (Pain, Non-pain).

The summary effect for each subgroup was calculated under random effects model incorporating RVE, similarly to the main analyses. However, the degrees of freedom for some subgroups fell below $\mathrm{df}=4$, which limits the interpretability of the results: Fun seeking - non-pain ( $\mathrm{df}=1.91)$, involving conditioning ( $\mathrm{df}=1.98)$; Reward responsiveness - non-pain ( $\mathrm{df}=1.98)$, involving conditioning $(\mathrm{df}=2.24)$; Empathic concern - involving conditioning ( $\mathrm{df}=2.77)$. Therefore, the results of these subgroup analyses should be taken as preliminary. Subgroups were then compared using random-effects meta-analysis. Results did not indicate a significant difference for any of the subgroup analyses (Table 2).

Table 2. Results of subgroup analyses

\begin{tabular}{|c|c|c|c|c|c|c|c|c|}
\hline \multirow[b]{2}{*}{ Subgroup } & \multirow[b]{2}{*}{ N studies } & \multirow[b]{2}{*}{$\mathrm{N}$ effect sizes } & \multicolumn{3}{|c|}{ Summary effect } & \multicolumn{3}{|c|}{ Heterogeneity } \\
\hline & & & $r$ & $95 \% \mathrm{CI}$ & $\mathbf{P}$ & $r_{\text {diff }}$ & $\mathbf{Z}$ & $\mathbf{P}$ \\
\hline \multicolumn{9}{|l|}{ Fun Seeking } \\
\hline Condition studied & & & & & & 0.06 & 0.77 & 0.44 \\
\hline Pain & 8 & 18 & 0.04 & {$[-0.12,0.20]$} & 0.59 & & & \\
\hline Non-pain & 3 & 5 & -0.03 & {$[-0.24,0.19]$} & 0.65 & & & \\
\hline Placebo manipulation method & & & & & & 0.20 & 0.94 & 0.35 \\
\hline Involving conditioning & 3 & 10 & 0.18 & {$[-0.63,0.80]$} & 0.49 & & & \\
\hline Not involving conditioning & 6 & 13 & -0.02 & {$[-0.11,0.07]$} & 0.52 & & & \\
\hline \multicolumn{9}{|l|}{ Reward Responsiveness } \\
\hline Condition studied & & & & & & 0.12 & 0.76 & 0.45 \\
\hline Pain & 9 & 22 & 0.09 & {$[-0.03,0.21]$} & 0.12 & & & \\
\hline Non-pain & 3 & 5 & -0.03 & {$[-0.59,0.55]$} & 0.87 & & & \\
\hline Placebo manipulation method & & & & & & 0.02 & 0.23 & 0.82 \\
\hline Involving conditioning & 4 & 10 & 0.11 & {$[-0.05,0.27]$} & 0.10 & & & \\
\hline Not involving conditioning & 6 & 17 & 0.09 & {$[-0.14,0.31]$} & 0.36 & & & \\
\hline \multicolumn{9}{|l|}{ Empathy - Empathic Concern } \\
\hline Placebo manipulation method & & & & & & 0.05 & 0.24 & 0.81 \\
\hline Involving conditioning & 4 & 9 & 0.05 & {$[-0.43,0.51]$} & 0.77 & & & \\
\hline Not involving conditioning & 7 & 7 & $<0.01$ & {$[-0.36,0.36]$} & 0.99 & & & \\
\hline
\end{tabular}

r=Pearson's $r$. rdiff=raw difference between subgroups, $Z=$ standardized difference between subgroups. 


\section{Sensitivity analyses}

In order to identify potential outlier effect sizes, we first performed influence tests for each metaanalysis, which identified one outlier for Reward Responsiveness (De Pascalis \& Scacchia, 2019) and Empathy - Fantasy (Corsi \& Colloca, 2017). No outliers were identified for any of the other traits. To assess sensitivity, we performed separate meta-analyses for 'Reward Responsiveness' and 'Empathy - Fantasy' with these effect sizes excluded. The results for both traits were statistically comparable with the original analyses (Reward Responsiveness: $r=0.06[-0.01,0.13], \mathrm{P}=0.07, \mathrm{I}^{2}=8.17 \%$; Empathy - Fantasy: $r<0.01[-0.13,0.14], \mathrm{P}=0.94, \mathrm{I}^{2}=0 \%$ ) (De Pascalis \& Scacchia, 2019).

Second, we conducted sensitivity analyses by re-running meta-analyses with unpublished data excluded. These analyses indicated slightly larger effect sizes for Behavioral inhibition $(r=0.10[0.03$, $\left.0.18], \mathrm{P}=0.02, \mathrm{I}^{2}=0 \%\right)$ and Reward responsiveness $\left(r=0.17[0.04,0.30], \mathrm{P}=0.02, \mathrm{I}^{2}=17.20 \%\right)$, compared to the original analyses. This is consistent with the tendency that unpublished results are more supportive of the null hypothesis, compared to published studies (Polanin et al., 2016).

\section{Impact of publication year and study quality}

We performed meta-regression to investigate effect of study quality and publication year on the absolute effect estimates. Observed effect sizes (Pearson's $r$ ) of the individual reports were plotted against study quality (Figure 3A) and publication year of included studies (from 2009 to 2020) (Figure 3B). Results indicated no significant effects of study quality $(B=0.01, P=0.58)$ or publication year $(\mathrm{B}=-0.01, \mathrm{P}=0.29)$.

A

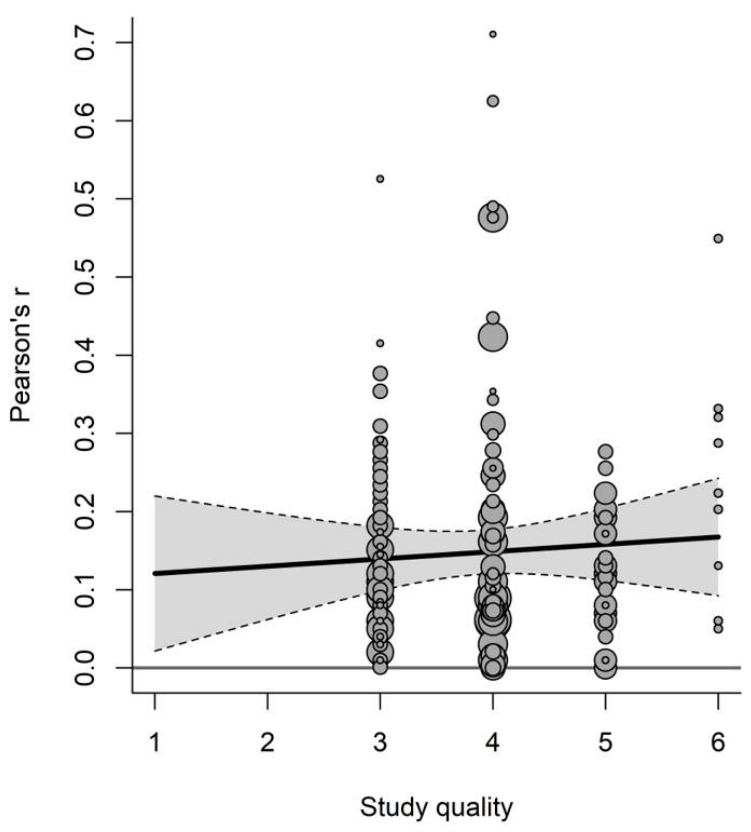

B

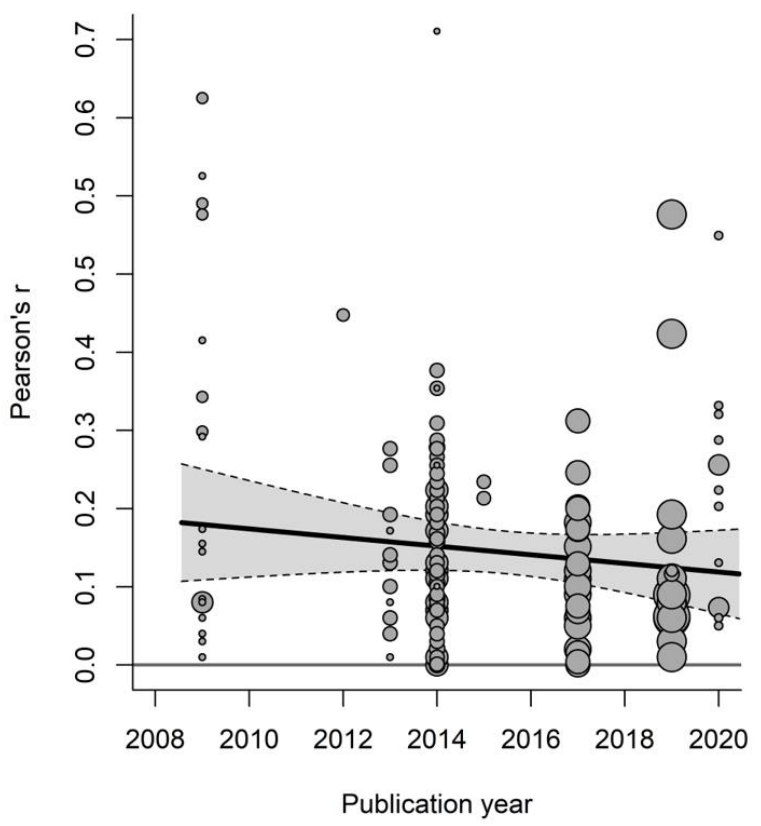

Figure 3. Meta-regression investigating the impact of study quality and publication year on outcomes, across all traits. Filled circles represent individual effect sizes, and circle sizes represent their corresponding weights in the regression model. The shaded area surrounding the regression line represents $95 \%$ confidence intervals. A) There was no significant association between study quality and effect size (Pearson's $r) B=0.0 \mathrm{I}(\mathrm{P}=0.58)$. $\mathrm{B}$ ) There was no significant association between publication year and effect size (Pearson's $r)(B=-0.01, P=0.29)$. 


\section{Risk of bias}

We developed a customized assessment tool to evaluate study quality (see Table S1). Next, we rated overall risk of bias based on study quality score of each study such that low, moderate, and high study quality correspond to high, moderate, and low risk of bias, respectively. Overall, we found the main reason for downgrading was the use of a single-blind design without assessing the success of blinding.

We assessed risk of reporting bias in syntheses with all personality traits collapsed to investigate the literature as a whole. We did not identify publication bias from the contour-enhanced funnel plot (Figure 4). An Egger's sandwich regression test confirmed that the observed effects did not indicate risk of reporting biases in the synthesized literature (B (se) $=0.71(0.61), P=0.14)$. In addition, we performed a sensitivity analysis using robust estimation to accommodate clustering, to estimate how much more likely affirmative studies are published compared to non-affirmative studies (Mathur \& VanderWeele, 2020). We defined studies as affirmative when the effect estimate was positive and statistically significant $(\alpha<0.05)$. We combined effect size estimates from all personality traits to assess the literature as a whole. For traits hypothesized to be negatively associated with placebo effects (i.e. Anxiety and Behavioral inhibition), the signs of effect estimates were therefore reversed prior to analysis. This analysis indicated that, for publication bias to shift the summary effect estimate to the null, affirmative studies would have to be 1.10 times more likely to be published than non-affirmative studies. This suggests that the primary meta-analytic results are robust to publication bias, which is in line with the results of the contour-enhanced funnel plot and the Egger's sandwich regression test.

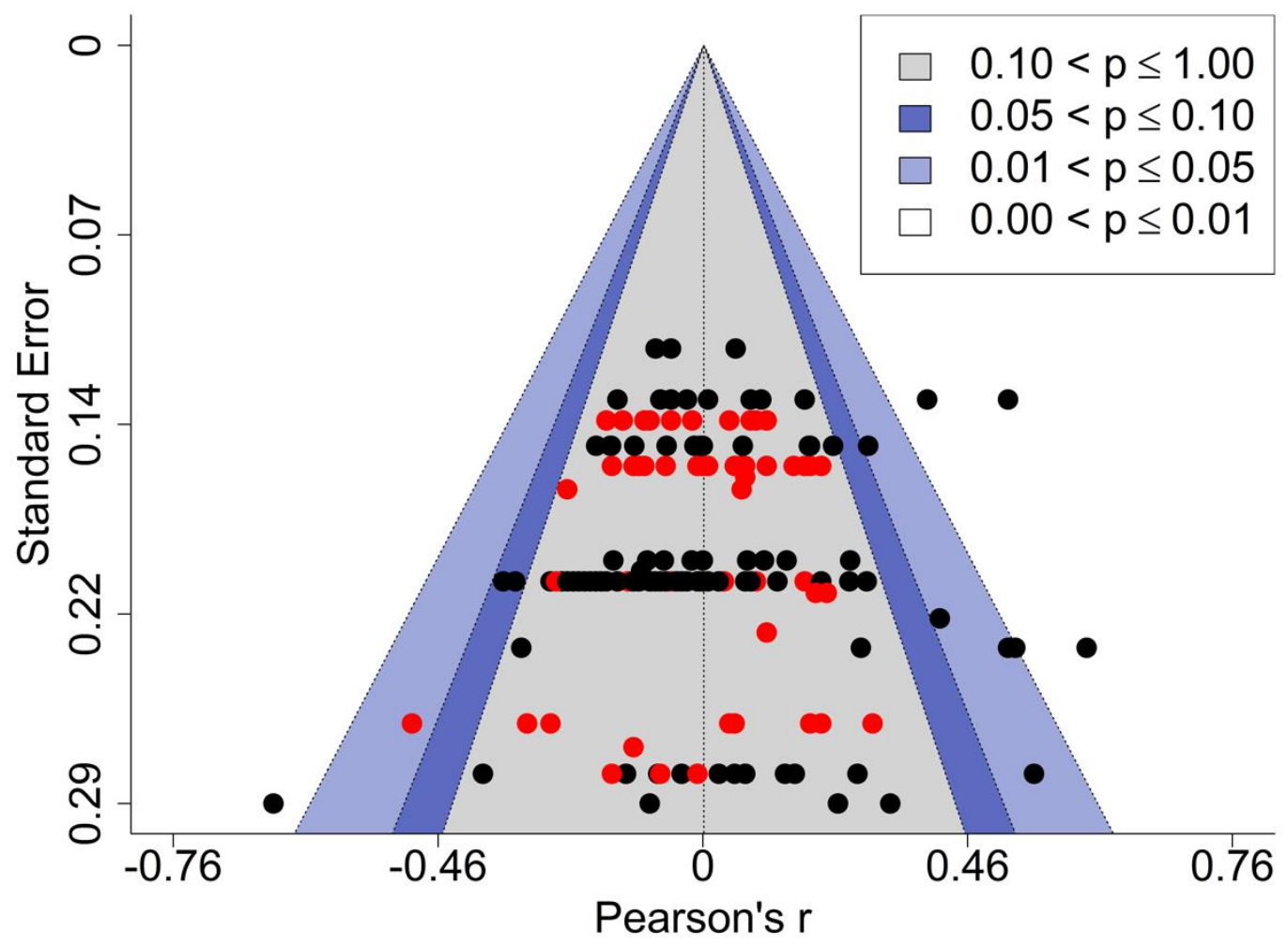

Figure 4. Contour-enhanced funnel plot. Effect sizes are plotted against their standard errors for visual inspection of publication bias. Published data are represented as black points and unpublished data and represented by red points. The vertical line represents the overall effect size, and the shaded areas represent bounds corresponding to different $p$-value cut-offs, as indicated in the key. The plot does not suggest asymmetry or risk of publication bias, which would be indicated by over-representation of data points in the contour-shaded areas. 


\section{Discussion}

Despite the common presumption that personality is a key factor for placebo responsiveness, our preregistered systematic review and meta-analyses did not find evidence that personality traits are associated with magnitude of placebo effects. This null finding applied to all traits assessed, and we did not find evidence that moderators such as condition (pain or non-pain) or placebo manipulation method (conditioning or non-conditioning) affected the association between personality and placebo effects. Moreover, equivalence tests supported the absence of any meaningful effects of medium-to-large magnitude for most traits, but we cannot exclude potentially small effects that may have been undetected due to insufficient power.

Overall, the results do not support the hypothesis that personality plays a meaningful role in shaping placebo effects. Thus, personality metrics, by themselves, do not appear promising as predictors of placebo responsiveness. More broadly, these results raise questions about whether there may be other dispositional factors that may influence placebo responding, or whether differences in placebo responsiveness are mostly due to situational and learning-based factors such as expectations (Corsi \& Colloca, 2017; Peerdeman et al., 2016), social context and rapport with the clinician (Ferreira et al., 2013; Kaptchuk et al., 2020; Kelley et al., 2009), attentional processes (Geers et al., 2006; Rossettini et al., 2018; Sprenger et al., 2012), mood and affect (Elsenbruch et al., 2019; Geers et al., 2019; Morton et al., 2009) or associative conditioning (Jensen et al., 2012; Montgomery \& Kirsch, 1997; Stewart-Williams \& Podd, 2004).

Several non-personality dispositional factors have been investigated. Genetic factors have been proposed to play a role in influencing the placebo effect (Hall et al., 2015). In particular, genetic variation in neurotransmitter systems that have been linked to placebo effects, e.g. endogenous dopamine (De la Fuente-Fernández et al., 2001; Scott et al., 2008), opioid (Pecina et al., 2015), serotonin (Furmark et al., 2008), and endocannabinoid functioning(Benedetti et al., 2011) have been highlighted as promising. Furthermore, relatively stable brain parameters such as cortical thickness (Vachon-Presseau et al., 2018), grey matter volume (Vachon-Presseau et al., 2018) and density (Schweinhardt et al., 2009) of cortical regions and subcortical nuclei, white-matter connectivity (Stein et al., 2012), and functional (resting state) network connectivity (Tétreault et al., 2016) have been linked with individual magnitude of placebo analgesia. While these findings are promising, the heterogeneity in methodology between these studies makes it challenging to identify factors that may generalize across different contexts. However, a recent meta-analytic effort synthesizing taskrelated fMRI from individual participants discovered a pattern of task-related circuitry associated with individual differences in placebo effects across heterogeneous studies (Zunhammer et al., 2021). Linking placebo outcomes with stable MRI parameters from this consortium dataset (structural MRI parameters and resting state network connectivity) may reveal potentially generalized dispositional brain parameters.

One interesting characteristic of the identified literature is that, while influential studies formulated hypotheses about "placebo reactor personality" as early as 1954 (Lasagna et al., 1954), the eligible studies were notably recent, with the earliest eligible study published in 2009. Importantly, we did not use any restrictions based on publication year. The primary reason for ineligibility for pre-2009 studies in this review was the lack of within-subjects assessment of placebo effects and the lack of a no-treatment control group. Another observation is that the majority of the included studies investigated placebo effects for pain - we identified 141 effect sizes that were pain-related and 30 non-pain outcomes (e.g. stress, tactile pleasantness, exercise performance). This is reflective of the experimental placebo literature as a whole, in which pain is most extensively studied, whereas less is known about placebo effects in other domains (Weimer et al., 2020).

The included studies had risk of bias ranging from low to high. We identified suboptimal experimental blinding as a key risk factor. Specifically, the majority of studies adopted single-blinded designs, in which participants were blinded to the condition (placebo/control) but the experimenter was not. This is concerning, given previous reports of that experimenters' expectations can affect patient outcomes (Chen et al., 2019; Gracely et al., 1985). In addition, most studies did not state whether blinding success was assessed. This is also a broader issue in randomized-controlled trials, in which unsuccessful blinding is a known source of bias (Fergusson et al., 2004).

For some personality traits, such as optimism, the outcomes of our syntheses may seem at odds with some previous systematic reviews (Horing et al., 2014; Jakšić et al., 2013; Kern et al., 2020). For example, a recent systematic review concluded that optimism may be a positive predictor of placebo responses, since a majority of the identified studies were consistent with a hypothesis that higher 
optimism/lower pessimism is associated with improved placebo response or reduced nocebo response (Kern et al., 2020). There are several differences in the selection process and general scope between our review and previous endeavors (Horing et al., 2014; Jakšić et al., 2013; Kern et al., 2020) that are worth discussing, and which may have contributed to these apparent discrepancies in outcomes.

First, we only included studies that used a no-treatment control for the placebo condition (i.e. "placebo effect"), which led to the exclusion of several studies (e.g. most clinical trials) that investigated "placebo responses" as operationalized in clinical trials, e.g. a change in symptoms after placebo treatment relative to a pre-placebo baseline (Horing et al., 2014; Jakšić et al., 2013; Kern et al., 2020). We applied this relatively strict eligibility criterion because we sought to minimize the influence of factors such as natural history, spontaneous remission, and regression to the mean (Fisher, 1967; McNair et al., 1979). For example, a positive association between a given trait and placebo response (change in pain after, relative to before, placebo treatment) could be driven by a tendency for such people to "naturally" recover more quickly, or show a higher frequency of fluctuations in symptomology, during a trial. Alternatively, such an effect could reflect a stronger tendency to sign up for a trial or research study when symptoms are particularly bad, relative to their usual state, increasing the risk of regression to the mean as a bias. The inclusion of a no-treatment condition controls for these factors when compared to a placebo treatment condition, and thus represents a less biased indicator of outcome change due to psychosocial processes (Kienle \& Kiene, 1997; Kirsch, 2013).

Second, we included unpublished studies in our study. While the inclusion of unpublished studies increases statistical power, such studies often show weaker statistical effects compared to published studies. Indeed, sensitivity analyses indicated that, for Behavioral inhibition and Reward responsiveness, there was a modest tendency toward lower effect sizes for unpublished relative to published studies. A common explanation is the file drawer effect, i.e. that researchers and journals are less inclined to publish null or negative findings compared to positive findings (Rosenthal, 1979). Thus, the inclusion of unpublished studies is thought to improve the accuracy of meta-analytic estimates, and is generally a recommended practice. There may of course other reasons for why studies are unpublished, including low study quality, methodological errors, or failed manipulation checks. However, this did not seem to characterize the current dataset. In fact, a direct comparison showed that unpublished studies were scored higher on study quality compared to published studies (published vs. unpublished: $\mathrm{t}(83.31)=-9.36, \mathrm{P}<0.001)$. Another possibility is that the unpublished relative to the published subsample may consist of more reports in which personality was a secondary or exploratory outcome. However, even for published reports, it is difficult to accurately assess post hoc whether an outcome was indeed a primary or secondary outcome originally, especially in nonpreregistered studies and in studies not including an a priori power analysis. Thus, we did not attempt to assess the impact of whether-or-not outcomes were primary or secondary.

Third, we focused on placebo effects in our meta-analyses, and did not consider studies investigating personality and nocebo effects (i.e. symptom worsening in response to placebo treatment). Although there may be overlapping processes involved, methodological approaches to induce placebo and nocebo effects are often very different, making them challenging to combine directly in a meta-analysis. Thus, we chose to limit the scope to placebo effects in this study. Consequently, several studies investigating associations between optimism/pessimism and nocebo effects were omitted(Corsi et al., 2016; Geers et al., 2005; Szemerszky et al., 2010).

Finally, since our meta-analyses synthesized correlation coefficients, we excluded studies using stratification or post-hoc subgrouping based on personality trait scores, e.g. comparing placebo effects between "high score" relative to "low score" groups (Geers et al., 2005). The heterogeneity of experimental designs and analysis approaches for stratification studies make them challenging to subject to formal meta-analysis, especially in combination with reports of correlation coefficients. Our approach has the advantage of utilizing non-reductionist individual gradations of both trait scores and placebo outcomes. Yet, it is possible that certain personality traits may have indirect nonlinear, conditional, or moderating effects on placebo responding, in combination with situational factors, that were not captured by our linear approach. For example, it has been proposed that placebo responding may depend on the degree to which environmental cues in the therapeutic context are congruent with individuals' "avoidance" and "approach"-related personality traits (Darragh et al., 2015). One study found a positive association between placebo improvement and trait extraversion, agreeableness and openness (approach-related traits), but only in the context of a warm 
therapist-patient interaction (Kelley et al., 2009). Another study found that participants with higher empathic concern showed stronger placebo analgesia when expectations were transmitted via social observation of others, but not in a "verbal suggestion alone" condition (Hunter et al., 2014).

We identified small-to-moderate heterogeneity between study effect sizes in our meta-analyses. To investigate the heterogeneity of effect estimates between studies, we sought moderators for empathic concern, fun-seeking behavior, and reward responsiveness, which met our criteria for subgroup analysis eligibility. Notably, prespecified subgroups did not differ significantly by studied condition (i.e. pain vs non-pain studies) and placebo manipulation method (i.e. involving vs not involving conditioning). While these findings do not provide supporting evidence for contextual moderators such as type of placebo paradigm, material, and manipulation method, these subgroup analyses are limited due to sample size. Thus, more research is needed to determine how personality may potentially interact with situational factors, such as situational expectancy and the patient-clinician interaction (Ellingsen et al., 2020), to shape placebo effects. One approach could be to launch a "many-labs" project similar to efforts in psychology (Klein et al., 2014, 2018), in order to yield enough statistical power to detect such nuanced effects.

In addition to these limitations, the number of included studies and their sample sizes were relatively limited and thereby meta-analyses may be underpowered to detect a small but meaningful effect. It should be also noted that we could not perform meta-analysis on other personality traits that have been linked to placebo effects (e.g. extraversion, neuroticism, pain catastrophizing) because the statistical power was insufficient to satisfy the assumptions of Robust Variance Estimation.

In conclusion, our systematic review and meta-analyses do not support an association between personality traits and placebo effects. This may suggest that individual variability in placebo responding may be better explained by situational and learning factors, or dispositional factors other than personality (e.g. genetic or stable brain phenotypes). However, due to a limited number of studies eligible for follow-up analyses into moderators such as condition (e.g. pain, non-pain), placebo manipulation method, and type of placebo, there may be potential interactions between personality and context factors that are eluded by the present approach. Given the substantial heterogeneity in study design in the current literature, a more structured large-scale approach may be necessary to investigate such potential personality-context interactions in placebo effects.

\section{Methods \\ Eligibility criteria}

We followed the Preferred Reporting Items for Systematic Reviews and Meta-Analyses (PRISMA) guidelines for reporting systematic reviews (Page et al., 2021). We surveyed the literature and included studies as eligible if they met all the following criteria: (1) inclusion of a no-treatment control condition (most randomized controlled trials, which usually lack a no-treatment control condition, were ineligible); (2) 'placebo effect' which was operationalized as the within-subject difference between a 'placebo' and a 'no-placebo/control' condition (i.e. studies in which the placebo effect is quantified as a between-group difference were ineligible); (3) individual assessment of personality/psychological traits (i.e. stratification studies comparing subgroups scoring "high" vs. "low" on a given trait were ineligible). In order to maximize statistical power and to account for publication bias, e.g. the file drawer effect (Rosenthal, 1979), we considered both published and unpublished data as eligible. Only publications in English language were included, and we applied no restrictions regarding publication year.

\section{Literature search}

Information sources and search strategy. Literature search was performed in two stages. In stage 1 , from 4 to 16 December 2020, primary studies and review articles were systematically searched on Web of Science, PubMed, Embase, Google Scholar, and the Journal of Interdisciplinary Placebo Studies (JIPS) database (https://jips.online/), in line with previous recommendations (Bramer et al., 2017). For Google Scholar, we used the first 200 results sorted by relevance. In stage 2, on 8 January 2021, we searched relevant reference lists within published research papers and review papers that were already identified from the first search, in order to identify potentially eligible studies that were neglected during stage 1. Finally, we contacted authors from studies that did not report collecting 
personality trait data, but which otherwise met the eligibility criteria, to request any eligible unpublished data.

Search terms were specified to retrieve studies that operationalize placebo effect and personality traits and report correlation as outcome (Table S2). From the preliminary literature search, we experienced that placebo response and placebo effect were interchangeably used to refer the operationalization of placebo effect in this thesis. Search keywords included therefore both 'placebo response' and 'placebo effect'.

Study selection and data collection. Results of the systematic literature search were recorded using Endnote version 9.3.3 (Clarivate, Philadelphia, US). After removing duplicates following the strategy suggested by Bramer et al. (Bramer et al., 2016), authors HK and MM independently screened titles, abstracts, and full-texts for inclusion. Ineligible studies were excluded in a stepwise process using the following order: (1) lack of no-treatment control condition; (2) 'placebo effect' not operationalized as within-subject difference between placebo and control condition (e.g. separate 'placebo' and 'control groups'); (3) no individual assessment of personality/psychological traits (e.g. only comparison between subgroups of participants with 'high' vs. 'low' trait scores). In the case of disagreement between the reviewers in this process, this was consulted with author DME and resolved through consensus.

Next, we extracted characteristics of studies: authors, publication year, sample size, demographics of participants (clinical vs non-clinical population, mean age, sex). Correlation coefficient (Pearson's r or Spearman's rho) of personality trait score and magnitude of placebo effect was extracted as the primary outcome. Experimental methods were also recorded: type of personality trait questionnaire, placebo manipulation method (conditioning, non-conditioning), target of placebo intervention (pain, anxiety, depression etc.), type of placebo treatment (drug, device, visual stimuli), and blinding (deceptive single-blinded, deceptive double-blinded, open-label).

We recorded 'placebo effect' outcomes if they reflected subjective or behavioral outcomes indicative of symptom improvement or other beneficial effect, ascribed to the administration of placebo (e.g., reduction in pain, improved anxiety/mood, increased positive affect, improved physical performance). Thus, we excluded any placebo-related change in biological/physiological metrics (e.g., brain activity or autonomic outflow), since these are not directly reflective of symptom improvement or other beneficial/desirable outcome. Any ambiguity was consulted with author DME for final decision.

In cases when potentially eligible correlational data were not reported in the published report, we contacted the corresponding author to request either the respective correlation coefficient or subject-level data on placebo effects and trait scores.

\section{Risk of bias assessment}

Most of the available tools for risk of bias assessment in meta-analyses are designed for clinical trials (e.g. Cochrane Collaboration's tool for assessing risk of bias in randomised trials (Higgins et al., 2011)), and not well fitted to experimental studies such as the literature reviewed here. Thus, we designed a custom study risk of bias assessment tool, based on a previous validated tool, the Oxford Quality Scoring system, which entails randomization, blinding and justification for data exclusion (Jadad et al., 1996) (for details, see Table S1).

Using this custom risk of bias tool, study risk of bias was independently assessed by two review authors (HK and MM). Any disagreement was solved through discussion and consulted with the author DM when consensus could not be reached. Total risk of bias was computed as sum of six criteria, which we broadly categorized into low (0-2), moderate (3-4), high (5-6) quality. These scores were interpreted as implicating high, moderate, and low risk of bias, respectively.

\section{Effect measures}

The effect size measure of interest was the correlation coefficient between the placebo effect and personality trait score. Since studies define the 'placebo effect' differently (e.g. placebo - control vs. control - placebo), we inversed the sign for relevant studies such that a positive correlation 
coefficient indicated that a higher trait score was associated with better outcome improvement (e.g., larger reduction in pain) in the placebo condition relative to control.

\section{Data synthesis}

Eligibility for each synthesis. Since studies have typically reported independent theoretical rationale for testing the association between placebo effect and a given trait, we performed separate primary meta-analyses for each identified trait. We pursued formal meta-analyses of traits when the final eligible sample included at least five effect sizes, in line with previous recommendations (Fu et al., 2008; Tipton, 2015), and satisfied the statistical assumptions of Robust Variance Estimation (See 'Multiple outcomes within a study' section). Using these criterion, primary meta-analyses were performed for following personality traits with a priori significance level, $\alpha=0.05$ : Behavioral inhibition, Fun seeking, Goal-drive persistence, Reward responsiveness, Empathic concern, Fantasy, Perspective-taking, Personal distress, Optimism, and Anxiety.

Data preparation. We extracted Pearson's r coefficients as the primary outcome. In cases where unpublished individual subject data was obtained, we calculated Pearson's $r$ coefficients based on those raw data. For studies that reported Spearman's rho, we converted these coefficients to Pearson's r (Rupinski \& Dunlap, 1996). All coefficients were then converted to Fisher's z for computing summary effects and confidence intervals, and were converted back to Pearson's $r$ for reporting purposes, as recommended by Borenstein et al. (2011). Effect sizes $r=0.10, r=0.20, r=0.30$ were interpreted as arbitrary levels for small, moderate and large effects, respectively, following Gignac and Szodorai's recommendation for individual difference studies (Gignac \& Szodorai, 2016).

Presentation of data synthesis. Characteristics of the identified studies were summarized in a table ordered by publication year (Table S3). Results of individual studies and data synthesis for each personality trait were presented in individual forest plots (Figures S1-S10). In each forest plot, individual studies were visualized by squares, indicating point estimates and $95 \%$ confidence intervals, and the size of squares representing the weight assigned to them. The summary effect size and its $95 \%$ confidence interval were displayed as polygon at the bottom of forest plot. The effects of all meta-analyses were summarized in a summary forest plot (Figure 2).

Model for data synthesis. All analyses were performed in RStudio (version 4.0.4). We used robumeta (version 2.0) (Fisher et al., 2017) for random-effects model meta-analysis with the Robust Variance Estimation; metafor (version 2.4-0) (Viechtbauer, 2015) for data visualization; pimeta (ver 1.1.3) (Nagashima et al., 2019) for prediction intervals; TOSTER (ver 0.3.4) (Lakens, 2017) for equivalence testing; PublicationBias (ver 2.2.0) (Mathur \& VanderWeele, 2020) for sensitivity analysis of publication bias.

Due to the use of different modes of placebo manipulation and outcome measures in each study, it was unlikely that populations in all studies included in this meta-analysis shared one single true effect. Therefore, the summary effect size and confidence interval were estimated using a randomeffects model. Under a random-effects model, it is assumed that observed difference between individual studies consists of sampling error and heterogeneity in true effect size. The between-studies heterogeneity was quantified and tested using $\mathrm{I}^{2}$-statistic, with the null hypothesis that there is no heterogeneity between studies. We conducted a relevant subgroup analyses when moderate heterogeneity was observed, $\mathrm{I}^{2}>25 \%$, following the Cochrane Handbook (Deeks et al., 2011).

We also computed prediction intervals to estimate the extent to which a true effect estimate from a future study might fall into based on the identified studies (Borenstein et al., 2011; Higgins et al., 2009). It represents the actual dispersion of effect sizes around the summary effect, providing an explanation for heterogeneity in addition to $\mathrm{I}^{2}$-statistic. In this review, 95\% prediction intervals were presented along with summary effect estimate and confidence intervals for each individual trait. 
Multiple outcomes within a study. Studies commonly report multiple outcome measures from the same dataset (e.g., the correlation between a given trait and separate placebo outcomes), which can lead to statistical dependency. We expected the main source of shared variance to be introduced by shared samples (e.g., different outcomes derived from the same sample and data collection), whereas we expected less dependence between effect sizes obtained from different groups, even when they were part of the same general data collection. Thus, multiple effect sizes from different experimental groups within a reported study were treated as independent. Multiple effect sizes from a study could also be observed when a study used two or more types of outcomes to measure placebo effect (e.g., pain intensity and pain unpleasantness), raising risk of shared variance.

We therefore conducted meta-analyses incorporating Robust Variance Estimation (RVE), a random-effects meta-regression developed to flexibly handle dependent effect size measures (Hedges et al., 2010). RVE can incorporate multiple dependent effect sizes within a study even without the knowledge of the correlation between effect sizes with adequate reliability, even with smaller samples (Tipton, 2015). We specified an intercept-only model to compute summary effect sizes. With the small sample adjustment, the degrees of freedom should be larger than 4 for reliable interpretation of the results. We used this parameter $(\mathrm{df}<4)$ as a decision criterion for whether-or-not to perform formal meta-analysis for a given trait (primary analyses).

Consideration of multiple comparisons. In meta-analytic investigations, it is common to perform multiple statistical comparisons, which may increase the risk of Type I errors. This is especially pertinent in the case of multiple equivalent or dependent comparisons assessing the same hypothesis, or in the case of exploratory analyses involving a large number of tests. There are several ways to account for this, though there is no consensus on which method is the most efficient. It is often suggested to use family-wise correction (Polanin \& Pigott, 2015) or use a lower alpha level than the commonly used $\mathrm{P}=0.05$, (i.e., $\mathrm{P}=0.01$ or $\mathrm{P}=0.005$ ) (Borenstein et al., 2011). However, an overly conservative correction can increase the risk of Type II errors (i.e. false negative results). In this investigation, we considered the main analyses (for each identified personality trait) as assessing relatively independent hypotheses for the association between personality and placebo effects, and thus did not apply correction for multiple comparisons with regard to the number of primary analyses.

Equivalence testing. We incorporated two one-sided tests procedure to statistically determine absence of a meaningful effect (Lakens, 2017). Levels for the smallest effect size of interest were set as $r=0.10$, $r=0.20, r=0.30$, based on Gignac \& Szodorai's recommendation for effect sizes in individual difference studies (Gignac \& Szodorai, 2016). Since TOSTmeta only supports Cohen's d effect size estimates, coefficients were converted to Cohen's d prior to equivalence tests.

Subgroup analyses. We performed subgroup analyses to investigate between-study variability. Subgroup factors were prespecified based on the previous studies that proposed that distinct mechanisms may be involved in different study conditions and characteristics (e.g. study condition (Pollo et al., 2011), type of placebo (Benedetti \& Dogue, 2015), and placebo manipulation method (Colloca \& Benedetti, 2009; Meissner \& Linde, 2018)). However, due to the limited sample size, we were not able to use the full specter of levels specified in the preregistration (e.g. social observation, verbal suggestion, conditioning, semantic priming for the factor "placebo manipulation method"). As a consequence, we reduced the granulation of levels, and used the following factors and levels: Condition (pain, non-pain), Placebo manipulation method (conditioning, non-conditioning), and Type of placebo (drug, device). For example, the condition "non-pain" comprised studies of stress, fear, and physical performance; "drug" included topical cream, pill, or nasal spray as placebos; "device" included sham acupuncture, sham TENS, and sham neurostimulation; and "non-conditioning" included studies that used verbal suggestion and social observation to induce placebo effects. After studies within each personality trait category were divided by a priori subgroup levels, a summary effect size for each level was calculated. These subgroup-level effect sizes were then used to quantify the magnitude of heterogeneity between subgroups. Heterogeneity was investigated using a random-effects model.

Additionally, we performed a separate meta-regression with study quality and publication year, to investigate whether study quality and year of publication affected reported effect sizes. These analyses were performed with all personality traits collapsed as we were interested at the impact of two potential moderators in the placebo effect literature as a whole. Since the hypothesized 
direction of the association differed between different traits, we used absolute values of effect estimates to conduct these analyses.

Sensitivity analyses. Sensitivity analyses were performed to evaluate whether the original results were robust to the decisions and assumptions made for the data synthesis. First, we used a leave-one-out method to assess the impact of outliers in the case that any outlier was identified from influence test (metafor package (Viechtbauer, 2015)). Second, for meta-analyses including unpublished data, we investigated whether summary effect sizes without unpublished data were substantially different from the original analyses.

Reporting bias assessment. Reporting bias can arise when studies tend to be disseminated based on direction of effect and its statistical significance. This may bias the reliability of summary effect size by increasing risk of under- or overestimate it. To examine reporting bias, we first generated a contour-enhanced funnel plot with all the traits collapsed (Peters et al., 2008; Sterne et al., 2011). However, funnel plot asymmetry does not necessarily indicate publication bias, and may reflect other sources of biases, between-study heterogeneity or randomness (Egger et al., 1997). Hence, we performed the Egger-sandwich regression test to investigate funnel plot asymmetry (Rodgers \& Pustejovsky, 2020). Next, we tested sensitivity to publication bias using a Robust Estimation approach, which can accommodate clustered effect sizes, in order to assess the severity of publication bias (Mathur \& VanderWeele, 2020). This analysis provides the likelihood of publication of affirmative study (i.e. a study effect favoring hypothesis and significant $(\mathrm{P}<0.05)$ ) that could attenuate the summary effect to the null $(\mathrm{r}=0)$. By comparing results from primary meta-analysis to a worst-case meta-analysis in which only non-affirmative studies are included, this approach quantifies the severity of publication bias. This approach assumes one-tailed selection either favoring positive or negative result, which we determined based on the general hypotheses for each trait in the assessed literature. Specifically, the assessed literature generally hypothesized the traits Fun seeking, Goaldrive persistence, Reward responsiveness (Schweinhardt et al., 2009), Empathic concern, Fantasy, Perspective-taking, Personal distress (Colloca \& Benedetti, 2009; Hunter et al., 2014; Valentini et al., 2014 ) and Optimism (Geers et al., 2005, 2007, 2010) to be positive predictors of placebo effects. We identified the traits Behavioral inhibition (Broelz et al., 2019) and Anxiety (Pecina et al., 2013) to be hypothesized to be negative predictors of placebo effects. Since we were interested in a general trend in the placebo personality literature, we inverted the sign of effect sizes for Behavioral inhibition and Anxiety, and performed the sensitivity analysis across all traits, under the assumption that publication bias favored positive and significant results over negative and non-significant results.

Registration and protocol. A preregistration of this meta-analysis protocol is publicly available in the PROSPERO database: (https://www.crd.york.ac.uk/prospero/display_rec-

ord.php?ID=CRD42020222637). PROSPERO is an international prospective register of systematic reviews of health-related outcome. The protocol was written following the Preferred Reporting Items for Systematic Reviews and Meta-Analyses - Protocol (PRISMA-P) (Moher et al., 2015). The contents of the protocol include the rationale, research question, inclusion criteria, and plan for the meta-analyses and additional analyses.

We made a change to eligibility criteria for running subgroup analysis. In the preregistration, we stated that subgroup analysis will be conducted when the number of effect sizes per subgroup $>10$. Instead, we performed subgroup analysis when (1) moderate or higher heterogeneity was observed, i.e., $\mathrm{I}^{2}>25 \%$, and (2) when eligibility to run a random-effects model meta-analysis, i.e., the number of studies in a subgroup were 5 or higher. This change in protocol was decided after the initial search and eligibility assessment, and before any statistical analysis was performed.

\section{Declaration of Conflicting Interests}

The author(s) declared no potential conflicts of interest with respect to the research, authorship, and/or publication of this article. 


\section{Funding}

This study was supported by the Research Council of Norway/Marie Sklodowska-Curie Actions (FRICON/COFUND240553/F20) and the South-Eastern Norway Regional Health Authority (2020040 and 2022086).

\section{Supplemental Material}

Individual effect size data (correlation coefficients) and corresponding meta-data for all eligible studies are publicly available on Open Science Framework (https://osf.io/u9j2k/). Supplemental material for this article is available online.

\section{References}

Ashar, Y. K., Chang, L. J., \& Wager, T. D. (2017). Brain Mechanisms of the Placebo Effect: An Affective Appraisal Account. Annual Review of Clinical Psychology, 13(1), 73-98. https://doi.org/10.1146/annurev-clinpsy-021815093015

Atlas, L. Y. (2021). A social affective neuroscience lens on placebo analgesia. Trends in Cognitive Sciences, 25(11), 992-1005. https://doi.org/10.1016/j.tics.2021.07.016

Beecher, H. K., Keats, A. S., Mosteller, F., \& Lasagna, L. (1953). The Effectiveness of Oral Analgesics (morphine, Codeine, Acetylsalicylic Acid) and the Problem of Placebo "Reactors" and "Non-Reactors." Journal of Pharmacology and Experimental Therapeutics, 109(4), 393-400.

Benedetti, F., Amanzio, M., Rosato, R., \& Blanchard, C. (2011). Nonopioid placebo analgesia is mediated by CB1 cannabinoid receptors. Nature Medicine, 17(10), 1228-1230. https://doi.org/10.1038/nm.2435

Benedetti, F., \& Dogue, S. (2015). Different Placebos, Different Mechanisms, Different Outcomes: Lessons for Clinical Trials. PLoS ONE, 10(11). https://doi.org/10.1371/journal.pone.0140967

Borenstein, M., Hedges, L. V., Higgins, J. P., \& Rothstein, H. R. (2011). Introduction to meta-analysis. John Wiley \& Sons.

Bosman, M., Elsenbruch, S., Corsetti, M., Tack, J., Simrén, M., Winkens, B., Boumans, T., Masclee, A., \& Keszthelyi, D. (2021). The placebo response rate in pharmacological trials in patients with irritable bowel syndrome: A systematic review and meta-analysis. The Lancet Gastroenterology \& Hepatology. https://doi.org/10.1016/S24681253(21)00023-6

Bramer, W. M., Giustini, D., de Jonge, G. B., Holland, L., \& Bekhuis, T. (2016). De-duplication of database search results for systematic reviews in EndNote. Journal of the Medical Library Association: JMLA, 104(3), 240.

Bramer, W. M., Rethlefsen, M. L., Kleijnen, J., \& Franco, O. H. (2017). Optimal database combinations for literature searches in systematic reviews: A prospective exploratory study. Systematic Reviews, 6(1), 245. https://doi.org/10.1186/s13643-017-0644-y

Broelz, E. K., Enck, P., Niess, A. M., Schneeweiss, P., Wolf, S., \& Weimer, K. (2019). The neurobiology of placebo effects in sports: EEG frontal alpha asymmetry increases in response to a placebo ergogenic aid. Sci Rep, 9(1), 2381. https://doi.org/10.1038/s41598-019-38828-9

Buckalew, L., Ross, S., \& Starr, B. J. (1981). Nonspecific factors in drug effects: Placebo personality. Psychological Reports, 48(1), 3-8.

Cabeleira, C. M., Steinman, S. A., Burgess, M. M., Bucks, R. S., MacLeod, C., Melo, W., \& Teachman, B. A. (2014). Expectancy bias in anxious samples. Emotion (Washington, D.C.), 14(3), 588-601. https://doi.org/10.1037/a0035899

Carver, C. S., \& White, T. L. (1994). Behavioral inhibition, behavioral activation, and affective responses to impending reward and punishment: The BIS/BAS Scales. Journal of Personality and Social Psychology, 67(2), 319-333. https://doi.org/10.1037/0022-3514.67.2.319

Chen, P.-H. A., Cheong, J. H., Jolly, E., Elhence, H., Wager, T. D., \& Chang, L. J. (2019). Socially transmitted placebo effects. Nature Human Behaviour, 3(12), 1295-1305. https://doi.org/10.1038/s41562-019-0749-5

Colloca, L., \& Benedetti, F. (2009). Placebo analgesia induced by social observational learning. PAIN®, 144(1-2), 2834.

Colloca, L., Petrovic, P., Wager, T. D., Ingvar, M., \& Benedetti, F. (2010). How the number of learning trials affects placebo and nocebo responses. Pain, 151(2), 430-439. https://doi.org/10.1016/j.pain.2010.08.007

Corsi, N., \& Colloca, L. (2017). Placebo and Nocebo Effects:The Advantage of Measuring Expectations and Psychological Factors. Frontiers in Psychology, 8, 1-11. https://doi.org/10.3389/fpsyg.2017.00308

Corsi, N., Emadi Andani, M., Tinazzi, M., \& Fiorio, M. (2016). Changes in perception of treatment efficacy are associated to the magnitude of the nocebo effect and to personality traits. Sci Rep, 6, 30671. https://doi.org/10.1038/srep30671

Darragh, M., Booth, R. J., \& Consedine, N. S. (2014). Investigating the 'placebo personality'outside the pain paradigm. Journal of Psychosomatic Research, 76(5), 414-421. 
Darragh, M., Booth, R. J., \& Consedine, N. S. (2015). Who responds to placebos? Considering the "placebo personality" via a transactional model. Psychology, Health \& Medicine, 20(3), 287-295. https://doi.org/10.1080/13548506.2014.936885

Davis, M. H. (1983). Measuring individual differences in empathy: Evidence for a multidimensional approach. Journal of Personality and Social Psychology, 44(1), 113.

De la Fuente-Fernández, R., Ruth, T. J., Sossi, V., Schulzer, M., Calne, D. B., \& Stoessl, A. J. (2001). Expectation and dopamine release: Mechanism of the placebo effect in Parkinson's disease. Science, 293(5532), 1164-1166.

De Pascalis, V., \& Scacchia, P. (2017). Personality and placebo analgesia during cold stimulation in women: A LowResolution Brain Electromagnetic Tomography (LORETA) analysis of startle ERPs. Personality and Individual Differences, 118, 64-70.

De Pascalis, V., \& Scacchia, P. (2019). The influence of reward sensitivity, heart rate dynamics and EEG-delta activity on placebo analgesia. Behavioural Brain Research, 359, 320-332. https://doi.org/10.1016/j.bbr.2018.11.014

Deeks et al. (2011, February). Chapter 10: Analysing data and undertaking meta-analyses. /handbook/current/chapter-10

Egger, M., Davey Smith, G., Schneider, M., \& Minder, C. (1997). Bias in meta-analysis detected by a simple, graphical test. BMJ : British Medical Journal, 315(7109), 629-634.

Eippert, F., Bingel, U., Schoell, E. D., Yacubian, J., Klinger, R., Lorenz, J., \& Büchel, C. (2009). Activation of the opioidergic descending pain control system underlies placebo analgesia. Neuron, 63(4), 533-543.

Ellingsen, D.-M. (2014). Central modulation of affective touch, pain and emotions in humans.

Ellingsen, D.-M., Isenburg, K., Jung, C., Lee, J., Gerber, J., Mawla, I., Sclocco, R., Jensen, K. B., Edwards, R. R., \& Kelley, J. M. (2020). Dynamic brain-to-brain concordance and behavioral mirroring as a mechanism of the patient-clinician interaction. Science Advances, 6(43), eabc1304.

Ellingsen, D.-M., Wessberg, J., Eikemo, M., Liljencrantz, J., Endestad, T., Olausson, H., \& Leknes, S. (2013). Placebo improves pleasure and pain through opposite modulation of sensory processing. Proceedings of the National Academy of Sciences, 110(44), 17993-17998.

Elsenbruch, S., Roderigo, T., Enck, P., \& Benson, S. (2019). Can a Brief Relaxation Exercise Modulate Placebo or Nocebo Effects in a Visceral Pain Model? Frontiers in Psychiatry, 10. https://doi.org/10.3389/fpsyt.2019.00144

Enck, P., Bingel, U., Schedlowski, M., \& Rief, W. (2013). The placebo response in medicine: Minimize, maximize or personalize? Nature Reviews Drug Discovery, 12(3), 191-204. https://doi.org/10.1038/nrd3923

Fergusson, D., Glass, K. C., Waring, D., \& Shapiro, S. (2004). Turning a blind eye: The success of blinding reported in a random sample of randomised, placebo controlled trials. Bmj, 328(7437), 432.

Ferreira, P. H., Ferreira, M. L., Maher, C. G., Refshauge, K. M., Latimer, J., \& Adams, R. D. (2013). The therapeutic alliance between clinicians and patients predicts outcome in chronic low back pain. Physical Therapy, 93(4), 470478. https://doi.org/10.2522/ptj.20120137

Fields, H. (2004). State-dependent opioid control of pain. Nature Reviews Neuroscience, 5(7), 565-575. https://doi.org/10.1038/nrn1431

Fisher, S. (1967). The placebo reactor: Thesis, antithesis, synthesis, and hypothesis. Diseases of the Nervous System, 28(8), 510.

Fisher, S., \& Fisher, R. L. (1963). Placebo response and acquiescence. Psychopharmacologia, 4(4), 298-301. https://doi.org/10.1007/BF00408185

Fisher, Z., Tipton, E., Zhipeng, H., \& Fisher, M. Z. (2017). Package 'robumeta.'

Frisaldi, E., Shaibani, A., \& Benedetti, F. (2018). Placebo responders and nonresponders: What's new? Pain Management, 8(6), 405-408. https://doi.org/10.2217/pmt-2018-0054

Fu, R., Gartlehner, G., Grant, M., Shamliyan, T., Sedrakyan, A., Wilt, T. J., Griffith, L., Oremus, M., Raina, P., Ismaila, A., Santaguida, P., Lau, J., \& Trikalinos, T. A. (2008). Conducting Quantitative Synthesis When Comparing Medical Interventions: AHRQ and the Effective Health Care Program. In Methods Guide for Effectiveness and Comparative Effectiveness Reviews. Agency for Healthcare Research and Quality (US).

http://www.ncbi.nlm.nih.gov/books/NBK49407/

Furmark, T., Appel, L., Henningsson, S., Ahs, F., Faria, V., Linnman, C., Pissiota, A., Frans, O., Bani, M., Bettica, P., Pich, E. M., Jacobsson, E., Wahlstedt, K., Oreland, L., Langstrom, B., Eriksson, E., \& Fredrikson, M. (2008). A Link between Serotonin-Related Gene Polymorphisms, Amygdala Activity, and Placebo-Induced Relief from Social Anxiety. Journal of Neuroscience, 28(49), 13066-13074. https://doi.org/10.1523/jneurosci.2534-08.2008

Geers, A. L., Close, S., Caplandies, F. C., \& Vase, L. (2019). A Positive Mood Induction for Reducing the Formation of Nocebo Effects from Side Effect Information. Annals of Behavioral Medicine: A Publication of the Society of Behavioral Medicine, 53(11), 999-1008. https://doi.org/10.1093/abm/kaz005 
Geers, A. L., Helfer, S. G., Kosbab, K., Weiland, P. E., \& Landry, S. J. (2005). Reconsidering the role of personality in placebo effects: Dispositional optimism, situational expectations, and the placebo response. Journal of Psychosomatic Research, 58(2), 121-127. https://doi.org/10.1016/j.jpsychores.2004.08.011

Geers, A. L., Helfer, S. G., Weiland, P. E., \& Kosbab, K. (2006). Expectations and Placebo Response: A Laboratory Investigation into the Role of Somatic Focus. Journal of Behavioral Medicine, 29(2), 171-178. https://doi.org/10.1007/s10865-005-9040-5

Geers, A. L., Kosbab, K., Helfer, S. G., Weiland, P. E., \& Wellman, J. A. (2007). Further evidence for individual differences in placebo responding: An interactionist perspective. Journal of Psychosomatic Research, 62(5), 563-570. https://doi.org/10.1016/j.jpsychores.2006.12.005

Geers, A. L., Wellman, J. A., Fowler, S. L., Helfer, S. G., \& France, C. R. (2010). Dispositional Optimism Predicts Placebo Analgesia. Journal of Pain, 11(11), 1165-1171. https://doi.org/10.1016/j.jpain.2010.02.014

Geisler, M., Herbsleb, M., Bär, K.-J., \& Weiss, T. (2020). Dissociation of Endogenous Pain Inhibition Due to Conditioned Pain Modulation and Placebo in Male Athletes Versus Nonathletes. Frontiers in Psychology, 11.

Gignac, G. E., \& Szodorai, E. T. (2016). Effect size guidelines for individual differences researchers. Personality and Individual Differences, 102, 74-78. https://doi.org/10.1016/j.paid.2016.06.069

Gracely, R. H., Dubner, R., Deeter, W. R., \& Wolskee, P. J. (1985). Clinicians' expectations influence placebo analgesia. Lancet (London, England), 1(8419), 43. https://doi.org/10.1016/s0140-6736(85)90984-5

Hall, K. T., Loscalzo, J., \& Kaptchuk, T. J. (2015). Genetics and the placebo effect: The placebome. Trends in Molecular Medicine, 21(5), 285-294. https://doi.org/10.1016/j.molmed.2015.02.009

Hedges, L. V., Tipton, E., \& Johnson, M. C. (2010). Robust variance estimation in meta-regression with dependent effect size estimates. Research Synthesis Methods, 1(1), 39-65. https://doi.org/10.1002/jrsm.5

Higgins, J. P., Altman, D. G., Gøtzsche, P. C., Jüni, P., Moher, D., Oxman, A. D., Savović, J., Schulz, K. F., Weeks, L., \& Sterne, J. A. (2011). The Cochrane Collaboration's tool for assessing risk of bias in randomised trials. Bmj, 343.

Higgins, J. P. T., Thompson, S. G., \& Spiegelhalter, D. J. (2009). A re-evaluation of random-effects meta-analysis. Journal of the Royal Statistical Society: Series A (Statistics in Society), 172(1), 137-159. https://doi.org/10.1111/j.1467-985X.2008.00552.x

Horing, B., Weimer, K., Muth, E. R., \& Enck, P. (2014). Prediction of placebo responses: A systematic review of the literature. Frontiers in Psychology, 5. https://doi.org/10.3389/fpsyg.2014.01079

Huber, A., Lui, F., \& Porro, C. A. (2013). Hypnotic susceptibility modulates brain activity related to experimental placebo analgesia. Pain, 154(9), 1509-1518. https://doi.org/10.1016/j.pain.2013.03.031

Hunter, T., Siess, F., \& Colloca, L. (2014). Socially induced placebo analgesia: A comparison of a pre-recorded versus live face-to-face observation. European Journal of Pain, 18(7), 914-922.

Jadad, A. R., Moore, R. A., Carroll, D., Jenkinson, C., Reynolds, D. J. M., Gavaghan, D. J., \& McQuay, H. J. (1996). Assessing the quality of reports of randomized clinical trials: Is blinding necessary? Controlled Clinical Trials, 17(1), 1-12.

Jakšić, N., Aukst-Margetić, B., \& Jakovljević, M. (2013). Does personality play a relevant role in the placebo effect? Psychiatria Danubina, 25(1), 0-23.

Jellinek, E. M. (1946). Clinical Tests on Comparative Effectiveness of Analgesic Drugs. Biometrics Bulletin, 2(5), 8791. https://doi.org/10.2307/3001983

Jensen, K. B., Kaptchuk, T. J., Kirsch, I., Raicek, J., Lindstrom, K. M., Berna, C., Gollub, R. L., Ingvar, M., \& Kong, J. (2012). Nonconscious activation of placebo and nocebo pain responses. Proceedings of the National Academy of Sciences, 109(39), 15959-15964.

Kaptchuk, T. J., Hemond, C. C., \& Miller, F. G. (2020). Placebos in chronic pain: Evidence, theory, ethics, and use in clinical practice. BMJ (Clinical Research Ed.), 370, m1668. https://doi.org/10.1136/bmj.m1668

Kaptchuk, T. J., Kelley, J. M., Deykin, A., Wayne, P. M., Lasagna, L. C., Epstein, I. O., Kirsch, I., \& Wechsler, M. E. (2008). Do "placebo responders" exist? Contemporary Clinical Trials, 29(4), 587-595.

https://doi.org/10.1016/j.cct.2008.02.002

Kelley, J. M., Lembo, A. J., Ablon, J. S., Villanueva, J. J., Conboy, L. A., Levy, R., Marci, C. D., Kerr, C. E., Kirsch, I., Jacobson, E. E., Riess, H., \& Kaptchuk, T. J. (2009). Patient and practitioner influences on the placebo effect in irritable bowel syndrome. Psychosom Med, 71(7), 789-797. https://doi.org/10.1097/PSY.0b013e3181acee12

Kern, A., Kramm, C., Witt, C. M., \& Barth, J. (2020). The influence of personality traits on the placebo/nocebo response A systematic review. Journal of Psychosomatic Research, 128. https://doi.org/10.1016/j.jpsychores.2019.109866

Kessner, S., Forkmann, K., Ritter, C., Wiech, K., Ploner, M., \& Bingel, U. (2014). The Effect of Treatment History on Therapeutic Outcome: Psychological and Neurobiological Underpinnings. PLoS ONE, 9(10), e109014. https://doi.org/10.1371/journal.pone.0109014 
Kienle, G. S., \& Kiene, H. (1997). The powerful placebo effect: Fact or fiction? Journal of Clinical Epidemiology, 50(12), 1311-1318.

Kirsch, I. (1985). Response expectancy as a determinant of experience and behavior. https://doi.org/10.1037/0003066X.40.11.1189

Kirsch, I. (2013). The placebo effect revisited: Lessons learned to date. Complementary Therapies in Medicine, 21(2), 102-104.

Klein, R. A., Ratliff, K. A., Vianello, M., Adams, R. B., Bahník, Š., Bernstein, M. J., Bocian, K., Brandt, M. J., Brooks, B., Brumbaugh, C. C., Cemalcilar, Z., Chandler, J., Cheong, W., Davis, W. E., Devos, T., Eisner, M., Frankowska, N., Furrow, D., Galliani, E. M., ... Nosek, B. A. (2014). Investigating Variation in Replicability. Social Psychology, 45(3), 142-152. https://doi.org/10.1027/1864-9335/a000178

Klein, R. A., Vianello, M., Hasselman, F., Adams, B. G., Adams, R. B., Alper, S., Aveyard, M., Axt, J. R., Babalola, M. T., Bahník, Š., Batra, R., Berkics, M., Bernstein, M. J., Berry, D. R., Bialobrzeska, O., Binan, E. D., Bocian, K., Brandt, M. J., Busching, R., ... Nosek, B. A. (2018). Many Labs 2: Investigating Variation in Replicability Across Samples and Settings. Advances in Methods and Practices in Psychological Science, 1(4), 443-490. https://doi.org/10.1177/2515245918810225

Lakens, D. (2017). Equivalence Tests: A Practical Primer for t Tests, Correlations, and Meta-Analyses. Social Psychological and Personality Science, 8(4), 355-362. https://doi.org/10.1177/1948550617697177

Lasagna, L., Mosteller, F., von Felsinger, J. M., \& Beecher, H. K. (1954). A study of the placebo response. The American Journal of Medicine, 16(6), 770-779.

Leigh, R., MacQueen, G., Tougas, G., Hargreave, F. E., \& Bienenstock, J. (2003). Change in Forced Expiratory Volume in 1 Second After Sham Bronchoconstrictor in Suggestible but Not Suggestion-Resistant Asthmatic Subjects A Pilot Study. Psychosomatic Medicine, 65(5), 791-795. https://doi.org/10.1097/01.PSY.0000079454.48714.1B

Lidstone, S. C., de la Fuente-Fernandez, R., \& Stoessl, A. J. (2005). The placebo response as a reward mechanism. Seminars in Pain Medicine, 3(1), 37-42. https://doi.org/10.1016/j.spmd.2005.02.004

Lund, K., Petersen, G. L., Erlandsen, M., De Pascalis, V., Vase, L., Jensen, T. S., \& Finnerup, N. B. (2015). The magnitude of placebo analgesia effects depends on how they are conceptualized. Journal of Psychosomatic Research, 79(6), 663-668. https://doi.org/10.1016/j.jpsychores.2015.05.002

Lyby, P. S., Aslaksen, P. M., \& Flaten, M. A. (2010). Is fear of pain related to placebo analgesia? Journal of Psychosomatic Research, 68(4), 369-377.

Maij, D. L. R., \& van Elk, M. (2018). Getting absorbed in experimentally induced extraordinary experiences: Effects of placebo brain stimulation on agency detection. Conscious Cogn, 66, 1-16. https://doi.org/10.1016/j.concog.2018.09.010

Mathur, M. B., \& VanderWeele, T. J. (2020). Sensitivity analysis for publication bias in meta-analyses. Journal of the Royal Statistical Society. Series C, Applied Statistics, 69(5), 1091-1119. https://doi.org/10.1111/rssc.12440

Mayberg, H. S., Silva, J. A., Brannan, S. K., Tekell, J. L., Mahurin, R. K., McGinnis, S., \& Jerabek, P. A. (2002). The Functional Neuroanatomy of the Placebo Effect. American Journal of Psychiatry, 159(5), 728-737. https://doi.org/10.1176/appi.ajp.159.5.728

McCrae, R. R., \& Costa, P. T. (2003). Personality in adulthood: A five-factor theory perspective. Guilford Press.

McNair, D. M., Gardos, G., Haskell, D. S., \& Fisher, S. (1979). Placebo response, placebo effect, and two attributes. Psychopharmacology (Berl), 63(3), 245-250. https://doi.org/10.1007/bf00433557

Meissner, K., \& Linde, K. (2018). Are blue pills better than green? How treatment features modulate placebo effects. International Review of Neurobiology, 139, 357-378.

Meyer, B., Yuen, K. S., Ertl, M., Polomac, N., Mulert, C., Büchel, C., \& Kalisch, R. (2015). Neural mechanisms of placebo anxiolysis. Journal of Neuroscience, 35(19), 7365-7373.

Meyer, B., Yuen, K. S. L., Saase, V., \& Kalisch, R. (2019). The Functional Role of Large-scale Brain Network Coordination in Placebo-induced Anxiolysis. Cerebral Cortex, 29(8), 3201-3210. https://doi.org/10.1093/cercor/bhy188

Moher, D., Shamseer, L., Clarke, M., Ghersi, D., Liberati, A., Petticrew, M., Shekelle, P., \& Stewart, L. A. (2015). Preferred reporting items for systematic review and meta-analysis protocols (PRISMA-P) 2015 statement. Systematic Reviews, 4(1), 1-9.

Montgomery, G. H., \& Kirsch, I. (1997). Classical conditioning and the placebo effect. Pain, 72(1-2), 107-113. https://doi.org/10.1016/s0304-3959(97)00016-x

Morton, D. L., Watson, A., El-Deredy, W., \& Jones, A. K. P. (2009). Reproducibility of placebo analgesia: Effect of dispositional optimism. Pain, 146(1-2), 194-198. https://doi.org/10.1016/j.pain.2009.07.026

Nagashima, K., Noma, H., Furukawa, T. A., \& Nagashima, M. K. (2019). Package 'pimeta.' 
Oken, B. S., Flegal, K., Zajdel, D., Kishiyama, S., Haas, M., \& Peters, D. (2008). Expectancy effect: Impact of pill administration on cognitive performance in healthy seniors. Journal of Clinical and Experimental Neuropsychology, 30(1), 7-17. https://doi.org/10.1080/13803390701775428

Page, M. J., McKenzie, J. E., Bossuyt, P. M., Boutron, I., Hoffmann, T. C., Mulrow, C. D., Shamseer, L., Tetzlaff, J. M., \& Moher, D. (2021). Updating guidance for reporting systematic reviews: Development of the PRISMA 2020 statement. Journal of Clinical Epidemiology, 134, 103-112.

Pecina, M., Azhar, H., Love, T. M., Lu, T. T., Fredrickson, B. L., Stohler, C. S., \& Zubieta, J. K. (2013). Personality Trait Predictors of Placebo Analgesia and Neurobiological Correlates. Neuropsychopharmacology, 38(4), 639-646. https://doi.org/10.1038/npp.2012.227

Pecina, M., Love, T., Hodgkinson, C. A., Goldman, D., Stohler, C., \& Zubieta, J. K. (2013). Implications of the human mu opioid receptor (OPRM1 A118G) polymorphism in the neurobiology of stress and placebo responses. Neuropsychopharmacology, 38(SUPPL. 2), S252-S253. https://doi.org/10.1038/npp.2013.279

Pecina, M., Love, T., Stohler, C. S., Goldman, D., \& Zubieta, J. K. (2015). Effects of the Mu Opioid Receptor Polymorphism (OPRM1 A118G) on Pain Regulation, Placebo Effects and Associated Personality Trait Measures. Neuropsychopharmacology, 40(4), 957-965. https://doi.org/10.1038/npp.2014.272

Peerdeman, K. J., Van Laarhoven, A. I. M., Keij, S. M., Vase, L., Rovers, M. M., Peters, M. L., \& Evers, A. W. M. (2016). Relieving patients' pain with expectation interventions: A meta-analysis. Pain, 157(6), 1179-1191. https://doi.org/10.1097/j.pain.0000000000000540

Peters, J. L., Sutton, A. J., Jones, D. R., Abrams, K. R., \& Rushton, L. (2008). Contour-enhanced meta-analysis funnel plots help distinguish publication bias from other causes of asymmetry. Journal of Clinical Epidemiology, 61(10), 991-996. https://doi.org/10.1016/j.jclinepi.2007.11.010

Petrovic, P., Kalso, E., Petersson, K. M., \& Ingvar, M. (2002). Placebo and opioid analgesia-imaging a shared neuronal network. Science, 295(5560), 1737-1740.

Polanin, J. R., \& Pigott, T. D. (2015). The use of meta-analytic statistical significance testing. Research Synthesis Methods, 6(1), 63-73. https://doi.org/10.1002/jrsm.1124

Polanin, J. R., Tanner-Smith, E. E., \& Hennessy, E. A. (2016). Estimating the Difference Between Published and Unpublished Effect Sizes: A Meta-Review. Review of Educational Research, 86(1), 207-236. https://doi.org/10.3102/0034654315582067

Pollo, A., Carlino, E., \& Benedetti, F. (2011). Placebo mechanisms across different conditions: From the clinical setting to physical performance. Philosophical Transactions of the Royal Society B: Biological Sciences, 366(1572), 17901798.

Rodgers, M. A., \& Pustejovsky, J. E. (2020). Evaluating meta-analytic methods to detect selective reporting in the presence of dependent effect sizes. Psychological Methods. https://doi.org/10.1037/met0000300

Rosen, A., Yi, J., Kirsch, I., Kaptchuk, T. J., Ingvar, M., \& Jensen, K. B. (2017). Effects of subtle cognitive manipulations on placebo analgesia-An implicit priming study. European Journal of Pain, 21(4), 594-604. https://doi.org/10.1002/ejp.961

Rosenthal, R. (1979). The file drawer problem and tolerance for null results. Psychological Bulletin, 86(3), 638-641. https://doi.org/10.1037/0033-2909.86.3.638

Rossettini, G., Emadi Andani, M., Dalla Negra, F., Testa, M., Tinazzi, M., \& Fiorio, M. (2018). The placebo effect in the motor domain is differently modulated by the external and internal focus of attention. Scientific Reports, 8(1), 12296. https://doi.org/10.1038/s41598-018-30228-9

Rupinski, M. T., \& Dunlap, W. P. (1996). Approximating Pearson product-moment correlations from Kendall's tau and Spearman's rho. Educational and Psychological Measurement, 56(3), 419-429. https://doi.org/10.1177/0013164496056003004

Ruscheweyh, R., Kuhnel, M., Filippopulos, F., Blum, B., Eggert, T., \& Straube, A. (2014). Altered experimental pain perception after cerebellar infarction. Pain, 155(7), 1303-1312. https://doi.org/10.1016/j.pain.2014.04.006

Saunders, B., Saito, T., Klosterhoff, R., De Oliveira, L. F., Barreto, G., Perim, P., Pinto, A. J., Lima, F., De Sa Pinto, A. L., \& Gualano, B. (2019). I put it in my head that the supplement would help me": Open-placebo improves exercise performance in female cyclists. PLoS ONE, 14(9), e0222982. https://doi.org/10.1371/journal.pone.0222982

Schedlowski, M., Enck, P., Rief, W., \& Bingel, U. (2015). Neuro-Bio-Behavioral Mechanisms of Placebo and Nocebo Responses: Implications for Clinical Trials and Clinical Practice. Pharmacological Reviews, 67(3), 697-730. https://doi.org/10.1124/pr.114.009423

Scheier, M. F., \& Carver, C. S. (1992). Effects of optimism on psychological and physical well-being: Theoretical overview and empirical update. Cognitive Therapy and Research, 16(2), 201-228.

https://doi.org/10.1007/BF01173489 
Scheier, M. F., Carver, C. S., \& Bridges, M. W. (1994). Distinguishing optimism from neuroticism (and trait anxiety, self-mastery, and self-esteem): A reevaluation of the Life Orientation Test. Journal of Personality and Social Psychology, 67(6), 1063.

Schenk, L. A., \& Colloca, L. (2020). The neural processes of acquiring placebo effects through observation. NeuroImage, 209, 116510. https://doi.org/10.1016/j.neuroimage.2019.116510

Schwarz, K. A., Pfister, R., \& Büchel, C. (2016). Rethinking Explicit Expectations: Connecting Placebos, Social Cognition, and Contextual Perception. Trends in Cognitive Sciences, 20(6), 469-480. https://doi.org/10.1016/j.tics.2016.04.001

Schweinhardt, P., Seminowicz, D. A., Jaeger, E., Duncan, G. H., \& Bushnell, M. C. (2009). The Anatomy of the Mesolimbic Reward System: A Link between Personality and the Placebo Analgesic Response. Journal of Neuroscience, 29(15), 4882-4887. https://doi.org/10.1523/jneurosci.5634-08.2009

Scott, A. J., Sharpe, L., Quinn, V., \& Colagiuri, B. (2021). Association of Single-Blind Placebo Run-in Periods With the Placebo Response in Randomized Clinical Trials of Antidepressants: A Systematic Review and Meta-analysis. JAMA Psychiatry. https://doi.org/10.1001/jamapsychiatry.2021.3204

Scott, D. J., Stohler, C. S., Egnatuk, C. M., Wang, H., Koeppe, R. A., \& Zubieta, J.-K. (2007). Individual Differences in Reward Responding Explain Placebo-Induced Expectations and Effects. Neuron, 55(2), 325-336. https://doi.org/10.1016/j.neuron.2007.06.028

Scott, D. J., Stohler, C. S., Egnatuk, C. M., Wang, H., Koeppe, R. A., \& Zubieta, J.-K. (2008). Placebo and Nocebo Effects Are Defined by Opposite Opioid and Dopaminergic Responses. Archives of General Psychiatry, 65(2), 220. https://doi.org/10.1001/archgenpsychiatry.2007.34

Shapiro, A. K., Mike, V., Barten, H., \& Shapiro, E. (1973). Study of the placebo effect with a self-administered placebo test. Comprehensive Psychiatry, 14(6), 535-548.

Shapiro, A. K., Struening, E. L., Barten, H., \& Shapiro, E. (1975). Correlates of placebo reaction in an outpatient population. Psychol Med, 5(4), 389-396. https://doi.org/10.1017/s0033291700057019

Sprenger, C., Eippert, F., Finsterbusch, J., Bingel, U., Rose, M., \& Büchel, C. (2012). Attention modulates spinal cord responses to pain. Current Biology: CB, 22(11), 1019-1022. https://doi.org/10.1016/j.cub.2012.04.006

Stein, N., Sprenger, C., Scholz, J., Wiech, K., \& Bingel, U. (2012). White matter integrity of the descending pain modulatory system is associated with interindividual differences in placebo analgesia. PAIN@, 153(11), 2210-2217.

Sterne, J. A. C., Sutton, A. J., Ioannidis, J. P. A., Terrin, N., Jones, D. R., Lau, J., Carpenter, J., Rucker, G., Harbord, R. M., Schmid, C. H., Tetzlaff, J., Deeks, J. J., Peters, J., Macaskill, P., Schwarzer, G., Duval, S., Altman, D. G., Moher, D., \& Higgins, J. P. T. (2011). Recommendations for examining and interpreting funnel plot asymmetry in meta-analyses of randomised controlled trials. BMJ, 343(jul22 1), d4002-d4002. https://doi.org/10.1136/bmj.d4002

Stewart-Williams, S., \& Podd, J. (2004). The placebo effect: Dissolving the expectancy versus conditioning debate. Psychological Bulletin, 130(2), 324-340. https://doi.org/10.1037/0033-2909.130.2.324

Sullivan, M. J., Lynch, M. E., Clark, A. J., Mankovsky, T., \& Sawynok, J. (2008). Catastrophizing and treatment outcome: Differential impact on response to placebo and active treatment outcome. Contemporary Hypnosis, 25(3-4), 129140. https://doi.org/10.1002/ch.365

Szemerszky, R., Köteles, F., Lihi, R., \& Bárdos, G. (2010). Polluted places or polluted minds? An experimental shamexposure study on background psychological factors of symptom formation in "Idiophatic Environmental Intolerance attributed to electromagnetic fields." International Journal of Hygiene and Environmental Health, 213(5), 387-394. https://doi.org/10.1016/j.ijheh.2010.05.001

Tang, B., Geers, A., Barnes, K., \& Colagiuri, B. (2019). Instrumental Control Enhances Placebo Analgesia. Journal of Pain, 20(12), 1486-1497. https://doi.org/10.1016/j.jpain.2019.05.013

Tétreault, P., Mansour, A., Vachon-Presseau, E., Schnitzer, T. J., Apkarian, A. V., \& Baliki, M. N. (2016). Brain connectivity predicts placebo response across chronic pain clinical trials. PLoS Biology, 14(10), e1002570.

Tipton, E. (2015). Small sample adjustments for robust variance estimation with meta-regression. Psychological Methods, 20(3), 375. https://doi.org/10.1037/met0000011

Trivedi, H., Madhukar, South, C., Jha, K., Manish, Rush, J., A., Cao, J., Kurian, B., Phillips, M., Pizzagalli, A., Diego, Trombello, M., Joseph, Oquendo, A., Maria, Cooper, C., Dillon, G., Daniel, Webb, C., Grannemann, D., Bruce, Bruder, G., Mcgrath, J., Patrick, Parsey, R., Weissman, M., \& Fava, M. (2018). A Novel Strategy to Identify Placebo Responders: Prediction Index of Clinical and Biological Markers in the EMBARC Trial. Psychotherapy and Psychosomatics, 87(5), 285-295. https://doi.org/10.1159/000491093

Vachon-Presseau, E., Berger, S. E., Abdullah, T. B., Huang, L., Cecchi, G. A., Griffith, J. W., Schnitzer, T. J., \& Apkarian, A. V. (2018). Brain and psychological determinants of placebo pill response in chronic pain patients. Nature Communications, 9(1), 1-15. 
Valentini, E., Martini, M., Lee, M., Aglioti, S. M., \& Iannetti, G. (2014). Seeing facial expressions enhances placebo analgesia. Pain, 155(4), 666-673. https://doi.org/10.1016/j.pain.2013.11.021

Viechtbauer, W., \& Viechtbauer, M. W. (2015). Package 'metafor.' The Comprehensive R Archive Network. Package 'Metafor'. Http://Cran. r-Project. Org/Web/Packages/Metafor/Metafor. Pdf.

Walach, H., Sadaghiani, C., Dehm, C., \& Bierman, D. (2005). The therapeutic effect of clinical trials: Understanding placebo response rates in clinical trials - A secondary analysis. BMC Medical Research Methodology, 5(1), 26. https://doi.org/10.1186/1471-2288-5-26

Weimer, K., Colloca, L., \& Enck, P. (2015). Placebo effects in psychiatry: Mediators and moderators. The Lancet Psychiatry, 2(3), 246-257. https://doi.org/10.1016/S2215-0366(14)00092-3

Weimer, K., Enck, P., Dodd, S., \& Colloca, L. (2020). Placebo and nocebo effects in psychiatry and beyond. Frontiers in Psychiatry, 11, 801.

Weimer, K., Hahn, E., Monnikes, N., Herr, A. K., Stengel, A., \& Enck, P. (2019). Are Individual Learning Experiences More Important Than Heritable Tendencies? A Pilot Twin Study on Placebo Analgesia. Frontiers in Psychiatry, 10. https://doi.org/10.3389/fpsyt.2019.00679

Whalley, B., Hyland, M. E., \& Kirsch, I. (2008). Consistency of the placebo effect. Journal of Psychosomatic Research, 64(5), 537-541. https://doi.org/10.1016/j.jpsychores.2007.11.007

Zorjan, S., Gremsl, A., \& Schienle, A. (2019). Interaction between disgust proness and perception of treatment efficacy predicts response to a disgust placebo. Psychiatria Danubina, 31(1), 102-105. https://doi.org/10.24869/psyd.2019.102

Zunhammer, M., Spisák, T., Wager, T. D., \& Bingel, U. (2021). Meta-analysis of neural systems underlying placebo analgesia from individual participant fMRI data. Nature Communications, 12(1), 1391.

https://doi.org/10.1038/s41467-021-21179-3 